\title{
TERRORISMO, YIHADISMO Y CRIMEN ORGANIZADO EN LA ESTRATEGIA GLOBAL DE SEGURIDAD DE LA UE.
}

\author{
Antonio Alonso 1 \\ UNISCI / Universidad CEU-San Pablo
}

\begin{abstract}
El terrorismo es considerado en la Estrategia Global para la Política Exterior y de Seguridad de la UE como una de las principales amenazas a la seguridad de la Unión Europea. La lucha contra el terrorismo ha dado sus frutos en los últimos quince años, pero este artículo analiza la nueva Estrategia y se pregunta si será suficiente para responder con eficacia a esta amenaza y si se están empleando todos los medios necesarios para atajarla.
\end{abstract}

Resumen:

Palabras clave: Terrorismo, Yihadismo, Crimen Organizado, Estrategia Global de Seguridad de la Unión Europea.

Title in English: Terrorism, Jihadism, Organized Crime in the Global Security Strategy of the European Union.

\section{Abstract:}

Terrorism is considered by the Global Strategy for Foreign Affairs and Security of the EU as one of the main threats for the security of the European Union. The battle against terrorism has achieved important results in the past fifteen years. This article analyses the new Strategy asking if it will be enough to respond effectively and efficiently to this threat and if all the available tools are being used to end with it.

Keywords: Terrorism, Jihadism, Organized Crime, the Global Security Strategy of the European Union

Copyright (C) UNISCI, 2016.

Las opiniones expresadas en estos artículos son propias de sus autores, y no reflejan necesariamente la opinión de UNISCI. The views expressed in these articles are those of the authors, and do not necessarily reflect the views of UNISCI.

\footnotetext{
${ }^{1}$ Antonio Alonso Marcos es profesor del Instituto de Humanidades "Ángel Ayala", Universidad CEU-San Pablo, e investigador de UNISCI.

E-mail:aalonso@ceu.es.

DOI: http://dx.doi.org/10.5209/RUNI.53785
} 


\section{Introducción.}

Entre 2009 y 2013 se produjeron un total de 1.010 atentados -sumando los fallidos y los consumados - en territorito de la UE, dejando 38 víctimas mortales. A partir del surgimiento del Estado Islámico (EI), esa cifra se ha incrementado de manera significativa, además de suponer un fuerte golpe a la moral europea con los atentados de París en la sala Bataclan, los atentados de Bruselas -la llamada "capital de Europa"- y los de Niza².

La Estrategia Global para la Política Exterior y de Seguridad de la UE de 2016 contempla el terrorismo ${ }^{3}$ como una de las principales amenazas para la Unión Europea (UE). Se mantiene la filosofía y las cuatro líneas de acción establecidas por la Estrategia de la UE de lucha contra el terrorismo (2005) (prevención, persecución, protección y respuesta), y eso a pesar de los atentados de origen - principalmente - yihadista. Es cierto que se han aprobado nuevos documentos que hablan sobre la prevención de la radicalización y otros que alertan sobre el peligro que suponen los "retornados", ciudadanos europeos o que han residido en Europa durante años que han ido a combatir del lado de los yihadistas y que podrían volver a territorio europeo con un expertise en materia de guerrilla urbana que podría ser un elemento desestabilizador para la seguridad europea.

\footnotetext{
${ }^{2}$ Los atentados contra los trabajadores del semanario satírico Charlie Hebdo el 7 de enero de 2015 fue reivindicado por Al Qaeda en la Península Arábiga aunque el Estado Islámico les calificó de héroes. Ver "El Estado Islámico califica de "héroes" a los autores del atentado en Francia", EFE, 8 enero 2015, en http://www.efe.com/efe/america/mundo/el-estado-islamico-califica-de-heroes-a-los-autores-del-atentado-enfrancia/20000012-2506339.
}

${ }^{3}$ La Decisión Marco 2002/475/JAI y la Decisión Marco 2008/919/JAI del Consejo de 28 de noviembre de 2008 por la que se modifica la Decisión Marco 2002/475/JAI sobre la lucha contra el terrorismo, dan una definición común de terrorismo para todos los Estados de la UE - pues dicha Decisión debe ser traspuesta a las legislaciones nacionales-. Según el art. 1.1 de la Decisión Marco 2002/475/JAI: "Todos los Estados Miembros adoptarán las medidas necesarias para que se consideren delitos de terrorismo los actos intencionados a que se refieren las letras a) a i) tipificados como delitos según los respectivos Derechos nacionales que, por su naturaleza o su contexto, puedan lesionar gravemente a un país o a una organización internacional cuando su autor los cometa con el fin de:

- intimidar gravemente a una población,

- obligar indebidamente a los poderes públicos o a una organización internacional a realizar un acto o a abstenerse de hacerlo,

- o desestabilizar gravemente o destruir las estructuras fundamentales políticas, constitucionales, económicas o sociales de un país o de una organización internacional;

a) atentados contra la vida de una persona que puedan tener resultado de muerte;

b) atentados graves contra la integridad física de una persona;

c) secuestro o toma de rehenes;

d) destrucciones masivas en instalaciones gubernamentales o públicas, sistemas de transporte, infraestructuras, incluidos los sistemas informáticos, plataformas fijas emplazadas en la plataforma continental, lugares públicos o propiedades privadas, que puedan poner en peligro vidas humanas o producir un gran perjuicio económico; e) apoderamiento ilícito de aeronaves y de buques o de otros medios de transporte colectivo o de mercancías; f) fabricación, tenencia, adquisición, transporte, suministro o utilización de armas de fuego, explosivos, armas nucleares, biológicas y químicas e investigación y desarrollo de armas biológicas y químicas;

g) liberación de sustancias peligrosas, o provocación de incendios, inundaciones o explosiones cuyo efecto sea poner en peligro vidas humanas;

h) perturbación o interrupción del suministro de agua, electricidad u otro recurso natural fundamental cuyo efecto sea poner en peligro vidas humanas;

i) amenaza de ejercer cualesquiera de las conductas enumeradas en las letras a) a h). 11

${ }^{4}$ Ver Bąkowski, Piotr y Puccio, Laura: “'Foreign fighters': Member States' responses and EU action in an international context”, European Parliamentary Research Service, febrero 2015, PE 548.980, en http://www.europarl.europa.eu/EPRS/EPRS-Briefing-548980-Foreign-fighters-FINAL.pdf. Ver también Hernández, Salvador: "European Authorities Overwhelmed As Hundreds Of ISIS Fighters Return Home", BuzzFeed News, 25 marzo 2016, en https:/www.buzzfeed.com/salvadorhernandez/europe-overwhelmed-byreturning-isis-fighters? utm term $=$. foMbKGzXB2\#.afnmw105o9. 
Como se verá en las conclusiones, la seguridad absoluta no existe y es, además, una cuestión muy compleja, condicionada por múltiples actores y factores. En el caso concreto de este artículo -terrorismo, yihadismo, crimen organizado - la cuestión no es menos compleja. Aunque hay que reconocer que las fuerzas del orden han abortado acciones terroristas en numerosas ocasiones ${ }^{5}$ y que, en ese sentido, la prevención ha funcionado, también es cierto que la lucha contra el terrorismo no puede circunscribirse sólo al ámbito policial ${ }^{6}$ o militar, sino que tiene que acometerse desde otras ópticas y perspectivas -comprehensive approach-, incluidas las socioeconómicas, antropológicas y culturales. En este sentido, es necesario trabajar también en el ámbito de las fuerzas políticas y la -ínfima- parte de la sociedad que apoya y/o justifica el terrorismo - especialmente el de origen yihadista-, culpando de ello a Occidente, al capitalismo, a las políticas de la burocracia comunitaria o a todo eso a la vez.

Al hilo de esto último, está la cuestión de la relación existente entre el Islam como religión y la ideología del yihadismo, si se retroalimentan o si una podría ser utilizada para acabar con la otra. En este sentido, se tomarán en cuenta los distintos estudios que hay en torno a esta cuestión $\mathrm{y}$, también, sobre el número de ataques y de víctimas mortales producidas por dichos ataques, si este yihadismo se da más en suelo occidental o en países musulmanes, si las víctimas son más bien de origen musulmán o no ${ }^{7}$.

Tampoco hay que perder de vista que el terrorismo es simplemente una táctica ${ }^{8}$ y que, en lo que se refiere al resultado final, en poco se diferencia la acción de un desequilibrado mental que provoca una masacre en una supermercado o en un campus universitario y la acción de un terrorista que le pega un tiro en la nuca a un periodista. Sí es más "sencillo" controlar la acción de un grupo -que tiene una estructura bien definida y una cadena de mando, unas comunicaciones, unos códigos, un modus operandi conocido - que la acción de un individuo aislado. En este sentido, el terrorismo yihadista guarda ciertas similitudes con el terrorismo anarquista, pues la ideología es la base de la acción, se busca la propaganda por el hecho, la orden de atacar ya está dada y sólo se entra en relación con el resto del grupo para buscar apoyo de algún tipo -logística, armamento, etc-. Por otro lado, está la cuestión de la reivindicación: ¿qué "fuerza", qué "valor" tiene una acción aislada si no está respaldada por una organización o por un movimiento más amplio? La noticia del musulmán que prendió fuego a una imagen de la Virgen María en Fontellas (Navarra) habría tenido más repercusión si hubiera revindicado tal acción en nombre del Estado Islámico 9.

\footnotetext{
${ }^{5}$ El Primer Ministro Manuel Valls aseguró en el programa “Grand rendez-vous” de Europe 1/iTELE/Les Echos que "Tous les jours, les services de renseignement, la police, la gendarmerie, tous les jours, déjouent des attentats, démantèlent des filières irako-syriennes". Ver "Manuel Valls estime que Nicolas Sarkozy «se trompe» sur le terrorismo", Le Figaro, 11 Septiembre 2016, en http://www.lefigaro.fr/actualite-france/2016/09/11/0101620160911ARTFIG00038-des-attentats-sont-dejoues-tous-les-jours-en-france-dit-manuel-valls.php.

${ }^{6}$ En 2013 se llevaron a cabo unos grandes ejercicios antiterroristas con fuerzas policiales. Ver "The ATLAS Network prepares for the biggest anti-terrorism exercise at EU level”, European Commission Press reléase, Bruselas, 17 abril 2013, en http://europa.eu/rapid/press-release IP-13-335 en.htm.

${ }^{7}$ Según el Global Terrorism Index de 2015 los diez países con más ataques terroristas son casi todos musulmanes: Iraq, Afganistán, Nigeria, Pakistán, Siria, India, Yemen, Somalia, Libia y Tailandia. Ver "The Global Terrorism Index", en http://www.worldatlas.com/articles/the-global-terrorism-index-countries-mostaffected-by-terrorist-attacks.html.

$\overline{8}$ "Terrorism is not an ideology or movement, but a tactic or a method for attaining political goals. This view is also reflected in the Council Framework Decision of 13 June 2002 on Combating Terrorism (2002/275/JHA)". Ver TE SAT 2007, p. 9.

${ }^{9}$ Ver "El marroquí que incendió la iglesia de Fontellas, detenido de nuevo tras atacar una cruz", La Gaceta, 14 Septiembre 2016, en http://gaceta.es/noticias/marroqui-incendio-iglesia-fontellas-detenido-nuevo-atacar-cruz14092016-1829.
} 
En este artículo se va a analizar cómo han evolucionado los planteamientos sobre el terrorismo a través de las distintas estrategias de seguridad de la UE, desde la de 2003 hasta la de 2016, qué documentos ha aprobado la UE, qué decisiones ha adoptado y, sobre todo, ver si todo eso ha sido eficaz y puede ayudar a evitar nuevas catástrofes como las de París, Bruselas o Niza en los años 2015 y $2016^{10}$. Además, se comparará con otros modelos de lucha contra el terrorismo en otros países.

\section{El nuevo yihadismo.}

Como muestra el Eurobarómetro (el $\mathrm{n}^{\mathrm{o}} 83$ ) de primavera de 2015, difundido en julio de ese mismo año, el terrorismo era la principal preocupación para el 17\% de los europeos, un $6 \%$ más con respecto al Eurobarómetro anterior, por detrás de temas como la inmigración, la situación económica, el desempleo y el estado de las finanzas públicas de los Estados Miembros ${ }^{11}$. Esto se debe, principalmente, a que los medios de comunicación insisten en la idea de que Europa está siendo atacada por la yihad global y de que el Estado Islámico (EI) se está haciendo fuerte en Irak y Siria ${ }^{12}$, cuando en realidad la mayoría de los ataques terroristas perpetrados en suelo europeo son los de motivación ultranacionalista, separatista o independentista, como se puede observar en los siguientes cuadros (Tabla 1 y 2), elaborados con datos tomados de los distintos informes del EU TE-SAT, la mayoría de los ataques terroristas son de origen nacionalista.

Desde la muerte de Bin Laden, el sello, la marca terrorista que le ha tomado el relevo al frente de la yihad global es el denominado EI. Este grupo yihadista sigue tácticas militares en el campo de batalla (como en Irak y Siria, aunque también en Libia) y tácticas de guerrilla (de golpear y esconderse). Pero, sobre todo, en Europa y EE.UU. usan tácticas suicidas, esto es, no les importa perder la vida en el ataque perpetrado o incluso se podría decir que uno de sus objetivos al perpetrarlo es precisamente perder la vida. Esto último se puede ver en varios ataques yihadistas en los que después de perpetrar el ataque no huyen, sino que se mantienen en el lugar, esperando a la policía o las cámaras - de TV o del móvil一; así sucedió en el atentado de Woolwich ${ }^{13}$ y en el de Rouen ${ }^{14}$.

\footnotetext{
${ }^{10}$ No hay que olvidar, no obstante, los atentados perpetrados por Mohamed Merah en marzo de 2012. Este había viajado a Pakistán entre 2010 y 2011, siendo adoctrinado allí por el grupo Harakat ul-Mujahidin. Un año antes, Anders Behring Breivik había dejado un reguero de sangre en Noruega en julio de 2011 con u ataque terrorista no yihadista.

${ }^{11}$ Sorprendentemente, el terrorismo es la preocupación principal en un país poco afectado directamente por el mismo: Rumania (28\%); y aparece en segundo lugar en otros cuatro países: Chequia (30\%), Malta (27\%), Bulgaria (25\%) y Polonia (22\%). Ver Eurobarómetro n ${ }^{\circ} 83$, p. 15.

${ }^{12}$ Ver Cortina, Gabriel: "Yihad global, inteligencia y comunicación estratégica", infodefensa.com, 20 julio 2016 , en http://www.infodefensa.com/es/2016/07/20/opinion-yihad-global-inteligencia-comunicacion-estrategica.php. No obstante, hay otros autores que afirman que Al Qaeda ha sabido esperar su momento y que las últimas derrotas del EI hará que se incline la balanza de la yihad global en favor de Al Qaeda. Ver Chulov, Martin: "AlNusra Front cuts ties with al-Qaida and renames itself', The Guardian, 28 julio 2016, en https:/www.theguardian.com/world/2016/jul/28/al-qaida-syria-nusra-split-terror-network; y ver también Molina, Pablo: "Por qué Al Qaeda sobrevivirá y el Estado Islámico no", Libertad Digital, 11 septiembre 2016, en http://www.libertaddigital.com/opinion/pablo-molina/por-que-al-qaeda-sobrevivira-y-el-estado-islamico-no79973/.

${ }^{13}$ Michael Adebolajo y Michael Adebowale acabaron con la vida de Lee James Rigby en plena calle con un cuchillo en Woolwich el 22 de mayo de 2013. Ver Hamilton, Fiona: "MI6 failed to check on torture claims by Lee Rigby killer”, The Times, 16 September 2016, en http://www.thetimes.co.uk/article/mi6-failed-to-check-ontorture-claims-by-lee-rigby-killer-rfc7cxhdp. Ver también "Cómo Anjem Choudary se convirtió en uno de los hombres más peligrosos del Reino Unido sin empuñar un arma”, $B B C, 20$ August 2016, en http://www.bbc.com/mundo/noticias-internacional-37108581.

${ }^{14}$ Adel Kermide asesinó al P. Jacques Hamel en su parroquia mientras celebraba la eucaristía. Ver Teruel, Ana: "Los terroristas que degollaron a un cura en Francia proclamaron ser del ISIS", El País, 27 julio 2016, en http://internacional.elpais.com/internacional/2016/07/26/actualidad/1469523416_957859.html.
} 
Tabla 1. Lucha contra el terrorismo en la UE

\begin{tabular}{|l|c|c|c|}
\hline \multicolumn{1}{|c|}{ Añ } & $\mathbf{N}^{\mathbf{0}}$ ataques perpetrados & $\mathbf{N}^{\mathbf{0}}$ detenciones & Personas juzgadas \\
\hline $\mathbf{2 0 0 6}$ & 498 & 706 & 303 \\
\hline $\mathbf{2 0 0 7}$ & 581 & 1044 & 331 \\
\hline $\mathbf{2 0 0 8}$ & 515 & 1009 & 359 \\
\hline $\mathbf{2 0 0 9}$ & 316 & 623 & 398 \\
\hline $\mathbf{2 0 1 0}$ & 249 & 611 & 307 \\
\hline $\mathbf{2 0 1 1}$ & 174 & 484 & 316 \\
\hline $\mathbf{2 0 1 2}$ & 219 & 537 & 400 \\
\hline $\mathbf{2 0 1 3}$ & 152 & 535 & 313 \\
\hline $\mathbf{2 0 1 4}$ & 201 & 774 & 444 \\
\hline $\mathbf{2 0 1 5}$ & 211 & 1077 & 514 \\
\hline
\end{tabular}

Fuente, Europol.

Tabla 2. Ataques terroristas sufridos por la UE según su tipología.

\begin{tabular}{|c|c|c|c|c|c|c|}
\hline Año & $\begin{array}{l}\text { Ataques } \\
\text { extrema } \\
\text { derecha }\end{array}$ & $\begin{array}{c}\text { Ataques } \\
\text { extrema } \\
\text { izquierda }\end{array}$ & $\begin{array}{c}\text { Ataques } \\
\text { nacionalistas }^{16}\end{array}$ & $\begin{array}{c}\text { Ataques } \\
\text { islamistas }^{17} \\
\text { o religiosos }\end{array}$ & $\begin{array}{c}\text { Origen no } \\
\text { especificado }^{18}\end{array}$ & Total \\
\hline 2006 & 1 & 55 & 424 & 1 & 17 & 498 \\
\hline 2007 & 1 & 21 & 532 & 2 & 25 & 581 \\
\hline 2008 & 0 & 28 & 397 & 0 & 16 & 441 \\
\hline 2009 & 4 & 40 & 237 & 1 & 12 & 294 \\
\hline 2010 & 0 & 45 & 160 & 3 & 41 & 249 \\
\hline 2011 & 1 & 37 & 110 & 0 & 26 & 174 \\
\hline 2012 & 2 & 18 & 167 & 6 & 26 & 219 \\
\hline 2013 & 0 & 24 & 84 & 0 & 44 & 152 \\
\hline 2014 & 0 & 13 & 67 & 2 & 117 & 199 \\
\hline 2015 & & & & 150 & & 151 \\
\hline
\end{tabular}

Fuente, Europol.

Pero, ¿por qué jóvenes nacidos y educados en Europa dan el paso a la violencia yihadista? ¿Cómo es posible que inmigrantes de segunda o tercera generación (hijos o nietos de quienes emigraron a Europa en los años70) se han adherido a grupos yihadistas? Esta es una cuestión que ha centrado la atención de muchos investigadores. En Francia, país que está siendo el más vapuleado por el terrorismo del EI, cuatro islamólogos llevan décadas investigando sobre la relación entre Islam y violencia en Europa: François Burgat, Jean-Pierre Filiu, Gilles Kepel y Olivier Roy ${ }^{19}$. Este último habla de la islamización del radicalismo mientras que Kepel habla

\footnotetext{
15 "The collected data for October-December 2005 and for the year 2006 concerned a total of 549 attacks, 128 terrorist activities, 810 arrested suspects and 303 trials in the EU'. TE SAT 2007, p. 11.

${ }^{16}$ La denominación ha ido variando a lo largo de estos años y ha hecho referencia también a los atentados separatistas o independentistas.

${ }^{17}$ Esta denominación también ha variado con el tiempo y a partir de 2011 por recomendación del Comité Económico y Social Europeo: "El CESE recomienda emplear, en los documentos oficiales de la Unión Europea y de los organismos especializados, la expresión «terrorismo por motivos de intolerancia, racismo y xenofobia» en lugar de «terrorismo islamista»". Ver el Dictamen cuyo ponente fue Pîrvulescu, Cristian: La política antiterrorista de la UE, SOC/388, Bruselas, 5 de mayo de 2011, DICTAMEN del Comité Económico y Social Europeo sobre la «Comunicación de la Comisión al Consejo y al Parlamento Europeo - La política antiterrorista de la UE: logros principales y retos futuros» COM (2010) 386 final, p. 1. En la actualidad se denomina "Religiously Inspired Terrorism", denominación que debe ser menos ofensiva que la propuesta por el CESE.

${ }^{18}$ En esta categoría se incluirían también los pocos ataques perpetrados por un asunto concreto, generalmente de tipo ambientalista o animalista.

${ }^{19}$ Ver Bonzon, Ariane: “L'univers impitoyable des experts en islam”, Slat, 6 marzo 2016, en http://www.slate.fr/story/115019/univers-impitoyable-experts-islam. Ver también Guillebaud, Jean-Claude: "La guerre froide des "Islamologues", Téléobs, 4 Abril 2016, en
} 
de la radicalización del Islam. Al comprobar que la mayoría de las personas que se han visto involucradas en este tipo de actos terroristas apenas han tenido más contacto con el mundo de la delincuencia que con el Islam, habrá que admitir que no es un proceso de radicalización de una fe, de un credo, sino de una conversión súbita y profunda en un tipo de personas que ya han cometido actos violentos. Según Roy, el problema del yihadismo en Europa es una cuestión de choque intergeneracional y de nihilismo - de falta de sentido para sus vidas-, y por lo tanto no sería una cuestión de choque cultural o de falta de integración sino un problema psicológico ${ }^{20}$.

Por otro lado, la tesis de Kepel mantiene la idea de que el problema en sí es la radicalización del Islam, con un claro transfondo teológico. Esta forma de ver el problema es compatible con la idea de que el Islam no es monolítico y hay interpretaciones más flexibles y otras más rígidas. Por supuesto, en el caso de los yihadistas, estaríamos ante musulmanes que se han radicalizado, que han recibido la predicación de un Islam muy radical.

Parece que ninguna de estas dos tesis da respuesta completa a todos y cada uno de los casos de terroristas yihadistas que ha habido en Europa en los últimos 30 años. La tesis de Kepel no es "políticamente correcta" al poner el dedo en la llaga e implicar a terceros Estados que han financiado y siguen financiando el salafismo y el wahabismo en Ocidente y otros lugares, contribuyendo a pudrir comunidades musulmanas enteras. Además, y aquí entra Burgat en la discusión, ambas tesis exoneran a Francia y a Occidente de cualquier responsabilidad en este fenómeno y puede que algo de implicación sí tengan. En opinión de Burgat $^{21}$, hay que tener en cuenta otro tipo de factores que pueden haber empujado a esos individuos a dar el salto a la violencia, tales como condicionantes geopolíticos, decisiones erróneas de la Política Exterior francesa -como la colonización y posterior descolonización o el papel que ha jugado Francia en Oriente Próximo, especialmente en Líbano y Siria-. Filiu iría más en esta última línea, criticando a Roy y Kepel por su ceguera, por entender que el yihadismo es un fenómeno desconectado del sufrimiento de los musulmanes en países de Oriente Medio; de hecho, critica que los muertos europeos sí llamen la atención en Europa, pero no las víctimas árabes ${ }^{22}$.

Como se ve, aparentemente sólo se pueden dar respuestas parciales a la cuestión de la radicalización y del fenómeno yihadista. Ni siquiera, los estudios cuantitativos, que intentan encontrar un patrón común -aunque sea estadísticamente-, han sido capaces de satisfacer

http:/teleobs.nouvelobs.com/polemique/20160331.OBS7505/la-guerre-froide-des-islamologues.html. Ver Daumas, Cécile: “Olivier Roy et Gilles Kepel, querelle française sur le jihadisme”, Liberation, 14 abril 2016, en http:/www.liberation.fr/debats/2016/04/14/olivier-roy-et-gilles-kepel-querelle-francaise-sur-lejihadisme 1446226. Ver, por último, Roy, Olivier: "Le djihadisme est une révolte générationnelle et nihiliste", Le Monde, 24 noviembre 2015, en http://www.lemonde.fr/idees/article/2015/11/24/le-djihadisme-une-revoltegenerationnelle-et-nihiliste 4815992 3232.html.

${ }^{20}$ Para ayudar a reflexionar en torno a este debate integración vs. trastorno mental o, en otras palabras, causas ideológicas vs. causas psicológicas, es aleccionador leer las biografías de algunas personas detenidas por terrorismo. Por ejemplo, la primera detención en España gracias a la trazabilidad de la financiación del terrorismo del EI fue en julio de 2016. La historia de estos tres hermanos involucrados en la yihad es muy aleccionadora, pues todos estaban integrados en la sociedad que les había acogido, habían fundado una familia, hablaban catalán,... ¿Qué pudo motivarles a uno a abandonar su puesto de trabajo y llevarse a su mujer y sus dos hijos a luchar a Siria y a los otros dos a organizar todo un entramado de financiación del EI? Ver Carranco, Rebeca: "Detenidos en Girona dos hermanos acusados de financiar al Estado Islámico", El País, 27 julio 2016 , en http://ccaa.elpais.com/ccaa/2016/07/27/catalunya/1469597840_983668.html.

${ }^{21}$ Ver Guillebaud, Jean-Claude: "La guerre froide des "Islamologues",op.cit..

${ }^{22}$ Ver Flores, Félix: "Jean-Pierre Filiu: "Hay que dar voz a los disidentes de la yihad"”, La Vanguardia, 9 julio 2015, en http://www.lavanguardia.com/internacional/20150709/54433804582/estado-islamico-daesh-yihadismojean-pierre-filiu.html. 
todos los casos. Por lo tanto, si el yihadismo puede tener múltiples orígenes será más difícil atajar el problema; más aún si no se quiere afrontar el problema en su totalidad sino sólo selectivamente, sin atender al fondo de este asunto -las causas ideológicas-, que sin embargo sí aparece en la Estrategia de la UE de lucha contra el terrorismo (2005). Este no es un asunto baladí pues la UE ya ha hecho una opción por una de las posturas de este debate sobre las causas ${ }^{23}$ y habla de la "prevención de la radicalización que conduce al extremismo violento":

Las causas que conducen a la radicalización pueden consistir en un fuerte sentimiento de desarraigo personal o cultural, una percepción de injusticia o humillación, agudizada por la marginación social, la xenofobia o la discriminación, posibilidades limitadas de educación o empleo, delincuencia, factores políticos, así como una dimensión ideológica y religiosa, vínculos familiares desestructurados, traumas personales u otros problemas psicológicos. Estos factores pueden ser explotados por los reclutadores, que aprovechan las vulnerabilidades y reivindicaciones para manipular, o reforzados, por el contrario, por el autoaislamiento ${ }^{24}$.

Esta es, sin duda una toma de posición debatible con notables implicaciones políticas y prácticas ${ }^{25}$ que deja fuera asuntos cruciales destacados por expertos no solo europeos. Dejando de lado aspectos teológicos, que acertadamente resalta el profesor Kepel, hay que enfatizar de nuevo la actuación de diversos Estados musulmanes financiando el wahabismo y salafismo con la construcción de mezquitas, el envío de imanes o asociaciones caritativas ${ }^{26}$ que han conducido al pudrimiento de zonas y Estados enteros, caso del Sahel, Kosovo, Marruecos, Túnez, sur de Filipinas o Indonesia, por poner unos ejemplos, dejando de lado la actuación en Libia, Siria y diversos Estados de la Unión Europea. Este tema ha sido de nuevo subrayado en Francia con motivo del cruel asesinato del anciano padre Jacques Hamel en Rouen. De nuevo, esta cuestión ha sido pasada por alto en los estudios financiados por la Comisión sobre el tema terrorista en la red Euromesco, existiendo incluso un informe del Parlamento europeo explícito y alarmante ${ }^{27}$.

\footnotetext{
23 “Con el fin de seguir recortando distancias entre las personas del mundo académico y los profesionales de la seguridad en este ámbito, la Comisión ha incluido temas de investigación sobre la radicalización y la inclusión en 2016 en el marco del programa Horizonte 2020 (Licitación de 8,5 millones EUR para desarrollar un enfoque global sobre la radicalización violenta en la Unión, que va desde la comprensión temprana hasta la mejora de la protección, y de 5 millones EUR sobre las tendencias de radicalización contemporáneas y sus implicaciones para Europa). También se han llevado a cabo investigaciones importantes sobre la diversidad religiosa en Europa (Licitación de 2,5 millones EUR sobre la diversidad religiosa en Europa: pasado, presente y futuro)". Ver "Comunicación de la Comisión al Parlamento Europeo, al Consejo, al Comité Económico y Social Europeo y al Comité de las Regiones. Apoyo a la prevención de la radicalización que conduce al extremismo violento", COM (2016) 379 final, Bruselas, 14 junio 2016, en http://eurlex.europa.eu/legal-content/ES/TXT/PDF/?uri=CELEX:52016DC0379\&qid=1469830069608\&from=ES, p. 5. ${ }^{24}$ Ibid, p. 4.

${ }^{25}$ Esto entra en colisión con el énfasis de la UE en la desradicalización como un asunto prioritario. A fin de cuentas Oliver Roy considera que la desradicalización no es la solución Véase Roy, Olivier: "La mort fait partie du project djihadiste", Le Monde, 11 octubre 2016.

${ }^{26}$ En este sentido, en verano de 2016 se conoció que una asociación marroquí radical -Justicia y

Espiritualidad - ha abierto un campus universitario, la primera Universidad de Ciencias Islámicas -dependiente de la Universidad de Minnesota- con el fin de difundir su visión radical del Islam en España. Ver "San Sebastián acoge una universidad islámica controlada por radicales", Libertad Digital, 8 septiembre 2016, en http://www.libertaddigital.com/espana/2016-09-08/san-sebastian-acoge-una-universidad-islamica-controladapor-radicales-1276582037/.

${ }^{27}$ Véase el informe del Departamento Político de la Dirección General para las Políticas Exteriores de la Unión (2013): The Involvement Of Salafism/Wahhabism In The Support And Supply Of Arms To Rebel Groups Around The World, en http://www.europarl.europa.eu/RegData/etudes/etudes/join/2013/457137/EXPOAFET_ET(2013)457137_EN.pdf.
} 


\section{La lucha contra el terrorismo en la UE desde 2003.}

El terrorismo fue contemplado como una de las grandes amenazas para la UE en la Estrategia Europea de Seguridad de 2003, "Una Europa segura en un mundo mejor". Después de la intervención en Afganistán se emprendió la intervención en Iraq a través de la Operation Iraqi Freedom, que formaba parte de la guerra contra el terror (GWoT). La Estrategia de 2003 ofrecía una visión del mundo que entroncaba con el (neo) idealismo o liberalismo institucional, que hacía una apuesta muy fuerte por la defensa de los valores europeos y el multilateralismo eficaz. En la Unión Europea no se aceptó la guerra contra el terror, asunto que ahora no es ya discutido en Estados como Francia.

En la Estrategia Europea de Seguridad de 2003 los planteamientos sobre terrorismo eran elementales. Decían así:

El terrorismo pone en riesgo vidas humanas, supone grandes gastos, pretende socavar la apertura y la tolerancia de nuestras sociedades y representa una creciente amenaza estratégica para toda Europa. Los movimientos terroristas cuentan cada vez más con abundantes recursos, están interconectados por redes electrónicas y están dispuestos a recurrir a la violencia sin límite y a causar incontables víctimas.

La más reciente oleada de terrorismo tiene un alcance mundial y está relacionada con el extremismo religioso violento. Surge de complejas causas, entre las que se encuentran la presión de la modernización, las crisis culturales, sociales y políticas y la alienación de los jóvenes que viven en sociedades extranjeras. ${ }^{28}$ Este fenómeno forma también parte de nuestra propia sociedad.

Europa es al mismo tiempo objetivo y base de este terrorismo: los países europeos son objetivos y han sufrido atentados. Se han descubierto bases logísticas de células de Al Qaeda en el Reino Unido, Italia, Alemania, España y Bélgica. Es indispensable una acción europea concertada. $^{29}$

Los planteamientos sobre las causas profundas dejaban de lado elementos esenciales que progresivamente se irán incorporando en documentos oficiales, como se señala más adelante, y que denotaban una notable superficialidad en los planteamientos. Además, como se ha comprobado posteriormente, esa visión del mundo quedó desfasada con la emergencia, ascenso y consolidación de otras potencias regionales -los llamados BRICS- que se están abriendo paso como potencias globales -especialmente China y, a otro nivel, Rusia-.

\subsection{La lucha contra el terrorismo en la UE.}

La lucha contra el terrorismo se ha desarrollado en la UE en dos ámbitos solapados e inseparables: acción exterior y asuntos de interior -también denominado "espacio de libertad, seguridad y justicia"-. El Programa de Tampere, refrendado por el Consejo Europeo los días 15 y 16 de octubre de 1999, tan sólo citaba de paso el tema del terrorismo: "El Consejo Europeo hace un llamamiento para que se creen sin demora equipos conjuntos de investigación tal como se contempla en el Tratado, como primer paso para luchar contra el tráfico de drogas y la trata de seres humanos, así como contra el terrorismo" 30 . Por su parte, el Programa de La Haya vino a sustituir al Programa de Tampere y fue el primer programa plurianual que fijó diez prioridades para conseguir un espacio de libertad, seguridad y justicia en la UE en un periodo de cinco años (2005-09). Sobre la lucha contra el terrorismo resumía el objetivo de la siguiente manera:

(2): trabajar en pos de una respuesta global. Se debe prestar especial atención a los diferentes aspectos de la prevención, la preparación y la respuesta con objeto de mejorar, y en caso necesario complementar, las capacidades de los Estados Miembros para luchar contra el terrorismo, en

\footnotetext{
${ }^{28}$ Énfasis añadido.

${ }^{29}$ Estrategia Europea de Seguridad de 2003, p. 3.

${ }^{30}$ Ver Consejo Europeo de Tampere, 15 y 16 de Octubre de 1999, Conclusiones de la Presidencia, en http://www.europarl.europa.eu/summits/tam_es.htm.
} 
aspectos pertinentes tales como la contratación de personal, la financiación, el análisis de riesgos, la protección de infraestructuras básicas y la gestión de las consecuencias ${ }^{31}$.

Más adelante, condensa en un párrafo cuáles serían los puntos fuertes de la lucha contra el terrorismo:

Es también primordial comprender el complejo fenómeno del terrorismo en Europa: los procesos de adoctrinamiento y captación y el tipo de entorno que permite que las ideas y movimientos terroristas echen raíces. Hay que incrementar los esfuerzos en la lucha contra la financiación del terrorismo. Los esfuerzos de los Estados Miembros y de la UE deben ser complementados por la cooperación exterior ${ }^{32}$.

Gracias a este Programa de La Haya se puso sobre la mesa lo que hoy se conoce como PNR (Registro de Nombres de Pasajeros) -que se explicará más adelante- y se lanzó la idea de elaborar el Programa específico: prevención, preparación y gestión de las consecuencias del terrorismo (2007-2013) 33 $^{33}$ a semejanza del Programa específico: Prevención y lucha contra la delincuencia (2007-2013) y el Programa europeo para la protección de infraestructuras críticas.

Desde 2003 se trabajó con una serie de instrumentos para luchar contra el terrorismo, fenómeno que entonces afectaba a Europa sólo en su versión de extrema derecha, de extrema izquierda o en su vertiente ultranacionalista; sólo de manera muy escasa y casi testimonial en su vertiente yihadista. En marzo de 2004 se creó la figura del coordinador de contraterrorismo y, posteriormente, una unidad contraterrorista en el SITCEN. El Consejo Europeo de 16 y 17 de diciembre de 2004 adoptó la Estrategia sobre financiación del terrorismo, revisada en 2008. En septiembre de 2005, la Comisión hizo público un documento para combatir la radicalización y el reclutamiento, documento que se actualizó en 2008, volviéndose sobre este asunto en enero de $2014^{34}$. En octubre de 2005, la Comisión hizo pública una Estrategia sobre la dimensión exterior del espacio de libertad, seguridad y justicia ${ }^{35}$.

En noviembre de 2005, se aprobó la Estrategia de la UE de lucha contra el terrorismo, basada en cuatro pilares: prevenir, proteger, perseguir y responder. Hay que subrayar que en la parte de la prevención hace hincapié en contrarrestar la radicalización y el reclutamiento de grupos terroristas como Al Qaeda y los grupos que esta organización inspiraba, considerando que este tipo de terrorismo representaba la principal amenaza para el conjunto de la Unión. El énfasis en el yihadismo se producía al calor de los atentados del 11-M (2004) en Madrid y, sobre todo, de los dos atentados en Londres de julio de 2005 (7-J y 21-J). Al mismo tiempo el

\footnotetext{
${ }^{31}$ Ver Comunicación de la Comisión Al Consejo y al Parlamento Europeo Programa de La Haya: Diez prioridades para los próximos cinco años. Una asociación para la renovación europea en el ámbito de la libertad, la seguridad y la justicia, COM (2005) 184 final, Bruselas, 10 mayo 2005, en http://eurlex.europa.eu/legal-content/ES/TXT/PDF/?uri=CELEX:52005DC0184\&from=es, p. 6.

${ }^{32}$ Ibídem, p. 8.

${ }^{33}$ Ver la Decisión del Consejo de 12 de febrero de 2007 por la que se establece para el período 2007-2013 el programa específico «Prevención, preparación y gestión de las consecuencias del terrorismo y de otros riesgos en materia de seguridad», integrado en el programa general «Seguridad y defensa de las libertades»", 2007/124/CE, Euratom, en http://eur-lex.europa.eu/legalcontent/ES/TXT/HTML/?uri=CELEX:32007D0124\&from=ES.

${ }^{34}$ Este documento combina medidas suaves (como los intercambios interculturales entre jóvenes) con medidas duras (como la prohibición de emisiones vía satélite que incitan al terrorismo). Ver la Comunicación de la Comisión al Parlamento Europeo y al Consejo sobre la captación de terroristas: afrontar los factores que contribuyen a la radicalización violenta, COM (2005) 313 final, Bruselas, 21 de septiembre de 2005, en http://eur-lex.europa.eu/legal-content/ES/TXT/PDF/?uri=CELEX:52005DC0313\&from=ES.

${ }^{35}$ Comunicación de la Comisión: "Hacia una estrategia sobre la dimensión exterior del espacio de libertad, seguridad y justicia”, COM (2005) 491 final, Bruselas, 12 octubre 2005, en http://eur-lex.europa.eu/legalcontent/ES/TXT/?uri=URISERV\%3Al16014.
} 
documento señalaba la importancia del factor ideológico y el papel de las ideologías extremistas, insistía en el combate contra la radicalización, mencionando una serie de condiciones que facilitaban esta radicalización, y en el combate contra el reclutamiento y la propaganda. Esta Estrategia de la UE de lucha contra el terrorismo establecía unas prioridades en la prevención que consideraba claves: el mal uso de internet; reclutamiento en prisiones, lugares de culto y formación religiosa; estrategia de comunicación; promoción del buen gobierno, democracia, educación y prosperidad económica; diálogo inter-cultural -sin mencionar el diálogo inter-religioso-, explicar mejor las políticas europeas, promover (por medio de programas de ayuda) el buen gobierno, la democracia, la educación y la prosperidad económica y continuar las investigaciones en este ámbito y compartir experiencias y análisis. El Plan de Acción contra el Terrorismo, aprobado en el Consejo Europeo de 12 de febrero de 2007 y revisado en 2011, vino a completar la estrategia de 2005.

El balance general que se puede hacer de la Estrategia de la Unión Europea de lucha contra el terrorismo (2005) es que era correcta en su análisis por varios motivos: señalaba el peligro de la radicalización y el reclutamiento; enfatizaba la importancia del factor ideológico; denunciaba que internet y la globalización ofrecían multitud de ventajas a los terroristas pero diversidad de obstáculos para que los Estados luchen contra ellos; y llamaba a una mayor cooperación entre los miembros de la UE, a que compartieran más información. Con esta Estrategia de 2005 se valoraba la labor de Europol y los informes TE-SAT (European Union Terrorism Situation and Trend Report). En diciembre de 2014 se llamó a la revisión de dicha Estrategia.

La Estrategia de la UE de lucha contra el terrorismo (2005) decía en su apartado $n^{\circ} 6$ que se centraba "en la lucha contra la radicalización y la captación en grupos terroristas como Al Qaeda y los grupos a quienes esta organización inspira, dado que este tipo de terrorismo representa actualmente la principal amenaza para la Unión en su conjunto". En efecto, este es un punto de gran importancia al señalar que el peligro al que se enfrenta la UE no es tanto el de un grupo organizado como podrían ser ETA, el IRA Auténtico, las Brigate Rosse o la banda Baader-Meinhof, sino que se trata de una ideología que inspira a personas que han sido radicalizadas en algún momento $\mathrm{y}$ han recibido formación especializada en campos entrenamiento. Hay que añadir que basta con que cualquier desequilibrado mental o cualquier persona que comulgue mínimamente con los ideales del EI o se sienta fascinado por los éxitos de este grupo, realice un acto violento y lo atribuya al EI para que éste lo pueda sumar a su lista de éxitos propio. En terminología de las Relaciones Internacionales esto sería un típico movimiento de "bandwagoning", que se aplica a los Estados débiles que se suben al carro del éxito de otro Estado más fuerte y le dejan que éste se enfrente con otro más poderoso.

¿Qué medidas se pueden proponer ante un terrorismo de este tipo? ¿Cómo se puede frenar a una persona que, en secreto, ha decidido atentar contra decenas de personas en nombre de Dios? Las medidas más socorridas son las disuasorias, especialmente aquellas que implican más presencia policial -o incluso militar- en las calles o ejercer un mayor control sobre la población, incluso en lo que se refiere a los contenidos de Internet y la "deep web" 36 , o la cooperación internacional, sobre todo en lo que se refiere a compartir información.

\footnotetext{
36 "The use of the Internet has become pivotal in all types of terrorism. It offers anonymity in the exchange of information, making it easy for these organisations to communicate and spread propaganda". Ver TE SAT 2009, p. 6.
} 
Un salto cualitativo, en cuanto al desarrollo y prevención de actos terroristas, se dio entre los años 2007-2008 ${ }^{37}$. Según los informes de Europol, fueron detenidas 26 personas -que tenían la intención de atentar en Italia, Afganistán, Irak y otros países árabes ${ }^{38}$ - a través de Eurojust en una operación internacional contra el terrorismo en Italia, Francia, Rumania, Portugal y el Reino Unido ${ }^{39}$. En 2008 esa cifra creció exponencialmente y fueron detenidas 1.009 personas en 13 países distintos, acusadas de terrorismo ${ }^{40}$.

En este contexto, la Estrategia Europea de Seguridad de 2003 sufrió una revisión en 2008 a través de un Informe de aplicación ${ }^{41}$ en el que ya se habla de ataques NBQR, ataques que de momento aún no han tenido lugar en Europa. En esta lucha contra el terrorismo intenta guardar el equilibrio entre la protección a los ciudadanos y el respeto a los derechos humanos y señala algunas prioridades para los años siguientes: "financiación del terrorismo, y en la definición de una política eficaz y exhaustiva de intercambio de información, teniendo debidamente en cuenta la protección de los datos personales" ${ }^{42}$. En este campo de la financiación, hay que reconocerlo, se han hecho avances -especialmente a instancias de las resoluciones de la ONU aprobadas tras el 11-S-, aunque aún queda bastante por hacer. También habla del diálogo intercultural: "Además, debemos redoblar los esfuerzos de lucha contra la radicalización y la captación de terroristas, haciendo frente a las ideologías extremistas y persiguiendo la discriminación. Es importante el papel del diálogo intercultural, en foros tales como la Alianza de Civilizaciones" ${ }^{43}$. En ese sentido, parece obvio que el foro adecuado no es dicha Alianza ${ }^{44}$ sino que es más eficaz un trabajo más intensivo sobre el terreno para evitar que se propaguen visiones radicales a través de redes sociales $\mathrm{y}$, principalmente, a través de mezquitas -en el caso del yihadismo ${ }^{45}$-. Nada se decía sobre el diálogo inter-religioso, y, también hay que repterirlo, poco se hizo para evitar la entrada de predicadores radicales financiados por otros Estados musulmanes, sobre todo Arabia Saudita y Catar $^{46}$. Esto último, tiene implicaciones directas en la seguridad, pues se ha trabajado en

\footnotetext{
${ }^{37}$ En 2007 se firmó el Tratado de Lisboa, pero no entró en vigor hasta el 1 de diciembre de 2009. En él se refuerza la llamada a la cooperación en la lucha contra el terrorismo y, especialmente, se llama a activar realmente una cláusula de solidaridad (art. $188 \mathrm{R}$ ).

${ }^{38}$ Según la Estrategia de 2016, la UE no olvida su compromiso con los derechos humanos a la hora de luchar contra el terrorismo dentro y fuera de sus fronteras: "Most crucially of all, the EU will live up to its values internally and externally: this is the strongest antidote we have against violent extremism”. Ver Estrategia Global para la Politica Exterior y de Seguridad de la UE (2016), p. 21.

${ }^{39}$ Ver Eurojust Informe Anual 2007, pp.34-35.

${ }^{40}$ Ver Europol TE-SAT Report 2009, p. 6.

${ }^{41}$ Ver Informe sobre la aplicación de la Estrategia Europea de Seguridad: Ofrecer seguridad en un mundo en evolución, S407/08, Bruselas, 11 de diciembre de 2008.

${ }^{4}$ Ibid, p. 4.

${ }^{43}$ Ibid.

${ }^{44}$ Pocos años más tarde, se dejará de lado dicha Alianza y se centrarán los esfuerzos en colaborar con el International Centre of Excellence for Countering Violent Extremism ("Hedayah") radicado en Abu Dabi y el Global Community Engagement and Resilience Fund (GCERF) localizado en Ginebra, además de participar en otros foros como la Cumbre Countering Violent Extremism celebrada en Washington DC en entre el 18 y el 20 de febrero de 2015. Ver "Outcome Of The Council Meeting", 3367th Council meeting of Foreign Affairs, Bruselas, 9 Febrero 2015, 6044/15, p. 8.

${ }^{45}$ Ver más adelante el papel de la EU Radicalisation Awareness Network (RAN).

${ }^{46}$ Al menos en España, la elección de imanes, de predicadores dirigentes de mezquitas, no tiene ningún control por parte de las autoridades, ni civiles ni religiosas. La Comisión Islámica de España no expide ningún permiso para que los imanes puedan actuar y por lo tanto desconocen cuál es la formación religiosa/intelectual que han recibido para predicar. Es cada comunidad, cada mezquita, quien, autónomamente elige a su propio imán por el método del "boca a boca", aunque se suelen seguir también criterios objetivos como la formación en una institución de prestigio (como la Universidad de Al Azhar de El Cairo) o llevar una vida coherente con el Islam. Obviamente, si la mezquita está sostenida económicamente por alguien, la opinión de ese "alguien" a la hora de elegir al imán tiene mucho peso.
} 
divulgar una versión del Islam muy radical y extremista, que ha derivado en proliferación de grupos fundamentalistas o en el surgimiento de células yihadistas ${ }^{47}$.

En mayo de 2010 el Consejo adoptó el Programa de Estocolmo: Una Europa abierta y segura que sirva y proteja al ciudadano, que establecía un plan de trabajo para la UE en el espacio de libertad, seguridad y justicia para el período 2010-2014. Este Programa recomendaba el desarrollo de una Estrategia de Seguridad Interior (ESI) que se centrara en la lucha contra la delincuencia transfronteriza, especialmente contra cinco bloques: trata de seres humanos; abuso sexual, explotación sexual de menores y pornografía infantil; delincuencia cibernética; delincuencia económica, corrupción, falsificación y piratería; y tráfíco de drogas. En cuanto a la lucha contra el terrorismo le dedica sólo un par de páginas, entre cuyos párrafos destacaría el siguiente:

"Se deben tomar medidas en la lucha antiterrorista en el marco del pleno respeto a los derechos y las libertades fundamentales, para que no susciten oposición estaría contemplado sólo en conexión con el crimen organizado. Además todas las partes interesadas deberían evitar estigmatizar a un colectivo específico de personas y deberían desarrollar el diálogo intercultural para promover el conocimiento y la comprensión mutuos". ${ }^{48}$

Este es un punto clave para entender la lucha contra el terrorismo dentro de la UE, que siempre debe guardar un equilibrio entre la persecución del criminal concreto y respetar los derechos humanos, incluidos los del propio acusado y/o condenado, además de evitar estigmatizar a un colectivo. Siguiendo este hilo argumental dirá posteriormente la Agenda Europea de Seguridad (2015): "La respuesta de la UE ante el extremismo no debe dar lugar a la estigmatización de ningún grupo o comunidad. Debe basarse en los valores comunes europeos de la tolerancia, la diversidad y el respeto mutuo, y promover comunidades libres y plurales. La UE debe atacar la base del terrorismo con un discurso alternativo fuerte y decidido" $"$.

En julio de 2010 la Comisión presentó un Panorama General de la gestión de la información en el espacio de libertad, seguridad y justicia en el que ofrece un elenco sumario de los instrumentos de la UE en aplicación, en ejecución o en consideración para la lucha contra el terrorismo: el Sistema de Información Schengen (SIS) y el Sistema de Información Schengen de segunda generación (SIS II); el sistema «Eurodac»; el Sistema de Información de Visados (VIS); la Directiva relativa a la información previa sobre pasajeros (API); el Convenio de Nápoles II; el Sistema de Información Aduanero (SIA) y su Base de datos de identificación de los expedientes aduaneros (FIDE). Otros instrumentos que tratan de prevenir y combatir el terrorismo y otras formas de delincuencia transfronteriza grave serían: la

\footnotetext{
${ }^{47}$ Ver Alonso Marcos, Antonio: "La lucha contra el terrorismo en España: Una estrategia a largo plazo", en Marquina Barrio, Antonio (ed) (2015): La Estrategia de Seguridad Nacional 2013: Un pavimento deslizante. Madrid, UNISCI, pp. 355-402.

${ }^{48}$ Ver Programa de Estocolmo: Una Europa abierta y segura que sirva y proteja al ciudadano, 2010/C 115/01, 4 mayo 2010, en http://eur-lex.europa.eu/legalcontent/ES/TXT/PDF/?uri=CELEX:52010XG0504(01)\&from=ES, pp. 24-25. Ver también la Comunicación de la Comisión al Parlamento Europeo, al Consejo, al Comité Económico y Social Europeo y al Comité de las Regiones - Garantizar el espacio de libertad, seguridad y justicia para los ciudadanos europeos Plan de acción por el que se aplica el programa de Estocolmo, COM/2010/0171 final, Bruselas, 20 abril 2010, en http://eurlex.europa.eu/legal-content/ES/TXT/PDF/?uri=CELEX:52010DC0171\&from=ES.

${ }^{49}$ Ver Comunicación de la Comisión al Parlamento Europeo, al Consejo, al Comité Económico y Social Europeo y al Comité de las Regiones. Agenda Europea de Seguridad, COM (2015) 185 final, Estrasburgo, 28 abril 2015, en http://eur-lex.europa.eu/legal-content/ES/TXT/PDF/?uri=CELEX:52015DC0185\&from=ES, p. 17.
} 
Decisión marco sobre la simplificación del intercambio de información entre los servicios represivos; la Decisión sobre la profundización de la cooperación transfronteriza; la Directiva 2006/24/CE sobre la conservación de datos; las Decisiones marco relativas a la consideración de las resoluciones condenatorias con motivo de un nuevo proceso penal y al intercambio de información de los registros de antecedentes penales, incluido el Sistema Europeo de Información de Antecedentes Penales (ECRIS) para la segunda; la Decisión del Consejo 2000/642/JAI relativa a las disposiciones de cooperación entre las unidades de información financiera de los Estados Miembros para el intercambio de información; la Decisión sobre la cooperación entre los Organismos de Recuperación de Activos (ORA); y las Plataformas de aviso contra la delincuencia informática ${ }^{50}$.

En noviembre de 2010 se aprobó la Estrategia de Seguridad Interior de la UE (2010$2014)^{51}$. Fue sometida a revisión periódica y se publicaron tres informes de seguimiento de su aplicación $^{52}$. En dicha Estrategia de 2010 se pone de relieve que una de las principales preocupaciones en materia de seguridad es la lucha contra el terrorismo, poniendo así de manifiesto el vínculo existente entre seguridad interior y exterior, especialmente en lo que se refiere a este tema:

La delincuencia aprovecha las condiciones ofrecidas por una sociedad globalizada, como las comunicaciones de alta velocidad, la alta movilidad y las transacciones financieras instantáneas. Asimismo, hay fenómenos que tienen un impacto transfronterizo sobre la seguridad dentro de la Unión Europea. Por lo tanto, hay una serie de amenazas comunes importantes que se pueden identificar: El terrorismo, en cualquiera de sus formas, manifiesta un desprecio absoluto por la vida humana y los valores democráticos. Su alcance global, sus consecuencias devastadoras, su capacidad de reclutamiento a través de la radicalización, así como la difusión de propaganda vía Internet y los diferentes medios mediante los que se financia, hacen del terrorismo una amenaza significativa y en constante evolución para nuestra seguridad ${ }^{53}$.

En 2015 se aprobaron otros dos documentos relevantes en esta materia: una nueva Estrategia de Seguridad Interior, que continuaba el camino iniciado por la aprobada en 2010, y a finales

\footnotetext{
${ }^{50}$ Ver la "Comunicación de la Comisión al Consejo y al Parlamento Europeo: Panorama general de la gestión de la información en el espacio de libertad, seguridad y justicia”, COM/2010/0385 final, Bruselas, 20 julio 2010, en http://eur-lex.europa.eu/legal-content/ES/TXT/PDF/?uri=CELEX:52010DC0385\&from=ES.

51 "Comunicación de la Comisión al Parlamento Europeo y al Consejo. La Estrategia de Seguridad Interior de la UE en acción: cinco medidas para una Europa más segura”, COM (2010) 673 final, Bruselas, 22 noviembre 2010, en http://eur-lex.europa.eu/legal-content/ES/TXT/PDF/?uri=CELEX:52010DC0673\&from=ES.

52 "En 2010 se establecieron tres acciones clave: 1) reforzar las comunidades para prevenir la radicalización y la captación; 2) reducir el acceso de los terroristas a la financiación y los materiales y seguir sus transacciones; y 3) proteger el transporte. En lo que respecta a la cooperación con las comunidades, las autoridades locales y la sociedad civil, la Comisión ha emprendido diversas acciones. La Comisión estableció en septiembre de 2011 la Red para la Sensibilización frente a la Radicalización (RSR), que capacita a los actores locales para abordar el problema de la radicalización y la captación39. En enero de 2014, la Comisión adoptó la Comunicación «Prevenir la radicalización hacia el terrorismo y el extremismo violento». Las acciones propuestas incluyen medidas de prevención y desarrollo de resistencias, así como para ayudar a las personas radicalizadas a desvincularse y desradicalizarse. Paralelamente, la Comisión publicó una recopilación de las mejores prácticas y enfoques observados por la RSR”. Ver "Comunicación de la Comisión al Parlamento Europeo y al Consejo. Informe final sobre la aplicación de la Estrategia de Seguridad Interior de la UE 2010-2014”, COM (2014) 365 final, Bruselas, 20 junio 2014, en

http://www.europarl.europa.eu/meetdocs/2014_2019/documents/com/com_com(2014)0365_com_com(2014)03 65 es.pdf, p. 7.

${ }^{53}$ Ver "Estrategia de Seguridad Interior de la Unión Europea: Hacia un modelo europeo de seguridad", Marzo de 2010, p. 13.
} 
de ese año también se aprobó la Agenda Europea de Seguridad 2015-202054, que identifica como prioritarias tres cuestiones: el terrorismo y la radicalización, el crimen organizado y el cibercrimen $^{55}$.

\subsection{El impacto de las revoluciones en los Estados árabes.}

Las revueltas de 2011 supusieron un punto de inflexión en la lucha contra el terrorismo. Desde ese año la inestabilidad creció en los Estados árabes, lo que acabó afectando a su entorno europeo, frenando la cooperación en la lucha antiterrorista con estos países o incluso deteriorándola -especialmente en el caso del caos libio-. Además, la llegada de Obama al poder hizo que EE.UU se fuera retirando de los escenarios bélicos y dejando la seguridad europea y de su entorno en manos de los propios europeos. Esto hizo que la situación se volviera menos manejable para las instituciones europeas y apenas han podido evitar que miles de europeos viajen a combatir a Iraq y Siria. Estos dos elementos -decisiones de Obama en Política Exterior y primaveras árabes - pusieron de manifiesto la división interna de la Unión, que se debate constantemente entre apostar por defender los intereses nacionales de cada Estado Miembro y defender los intereses de la Unión. Aún más se puso en evidencia cuando la inestabilidad y la emergencia humanitaria hizo que estallara la crisis de los refugiados.

Todo esto aparece en el seno de la Unión, no en las distintas Estrategias sino en comunicaciones y otros documentos, que tienen más dosis de realismo:

La UE y sus Estados Miembros se enfrentan a importantes desafíos en materia de seguridad. El terrorismo, la delincuencia organizada y la ciberdelincuencia suponen para las sociedades de toda Europa crecientes amenazas cuya naturaleza y magnitud han evolucionado. Europa tiene que afrontar los efectos colaterales de la inestabilidad política en su vecindad inmediata, que pone en peligro los intereses de seguridad de la UE. ${ }^{56}$

Aun así, las estrategias de seguridad interior -tanto la de 2010 como la de 2015 - parecen mejor elaboradas que las de acción exterior, más pegadas a la realidad. No obstante, en lo que se refiere al terrorismo y el crimen organizado, se comparten los medios que la Unión pone en marcha para luchar contra ambos fenómenos:

La Agenda Europea de Seguridad ayudará a los cuerpos de policía y de seguridad de los distintos Estados Miembros a proceder con mayor eficacia al intercambio de datos y a mejorar su cooperación en la lucha contra la delincuencia transfronteriza. Los Estados Miembros pueden recabar el apoyo de las agencias de la UE. Concretamente, la Agenda centra sus esfuerzos en crear valor añadido de la UE a través de las medidas siguientes:

A) facilitar el intercambio de información entre las autoridades policiales y judiciales y las agencias de la UE:

\footnotetext{
54 “La Comisión adoptó el 28 de abril de 2015 la Agenda Europea de Seguridad, que se presentó al Parlamento Europeo y al Consejo como base para Estrategia de Seguridad Interior renovada. El Consejo JAI adoptó el 16 de junio de 2015 unas Conclusiones del Consejo sobre la renovación de la Estrategia de Seguridad Interior de la UE 2015-2020, que se basan en la Agenda y tienen en cuenta la contribución del Parlamento Europeo a la

renovación de la Estrategia de Seguridad Interior". Ver Preguntas parlamentarias, 23 de septiembre de 2015, E007589/2015, Respuesta del Sr. Avramopoulos en nombre de la Comisión, en http://www.europarl.europa.eu/sides/getAllAnswers.do?reference=E-2015-007589\&language=ES.

${ }^{55}$ Ver "European Agenda on Security - State of Play", European Commission - Fact Sheet, MEMO/15/6115, Bruselas, 17 noviembre 2015, en http://europa.eu/rapid/press-release_MEMO-15-6115_en.htm.

${ }^{56}$ Ver "Agenda Europea de Seguridad: preguntas y respuestas", MEMO/15/4867, Estrasburgo, 28 abril 2015, en http://europa.eu/rapid/press-release_MEMO-15-4867_es.htm, p. 1.
} 
Ejemplo 1: El Sistema de Información de Schengen (SIS)

Ejemplo 2: El Sistema Europeo de Información sobre Antecedentes Penales (ECRIS)

B) mejorar la cooperación policial operativa:

Ejemplo 1: Los equipos conjuntos de investigación (ECI)

Ejemplo 2: Las agencias de la UE y, en particular, Europol y Eurojust, desempeñan un papel crucial a la hora de facilitar las labores de cooperación e investigación transfronterizas.

C) impulsar la formación y la cofinanciación de la seguridad a nivel de la UE:

Ejemplo 1: El Fondo de Seguridad Interior (FSI) para el período 2014-2020, recientemente creado, cuenta con un presupuesto total de aproximadamente 3800 millones EUR.

Ejemplo 2: La Comisión reforzará los medios de la Escuela Europea de Policía (CEPOL) ${ }^{57}$.

Pero fue la inestabilidad originada por las primaveras árabes y el uso de los campos de batalla de Libia, Irak y Siria como auténticos campos de entrenamiento, los que sirvieron en bandeja a los yihadistas la oportunidad para mejorar sus habilidades y capacidades y para cometer más atentados y más impactantes. En ese momento se constató que Catherine Ashton había optado por un perfil demasiado bajo en estas cuestiones de la lucha de la UE contra el terrorismo $^{58}$, de manera que los líderes de la UE encargaron a la nueva Alta Representante de la UE para Asuntos Exteriores y Política de Seguridad y Vicepresidente de la Comisión, Federica Mogherini, la elaboración de una nueva Estrategia en la que el terrorismo y la radicalización tuvieran un perfil más acusado. Así, Federica Mogherini presentó en junio de 2015 ante el Consejo Europeo el informe señalando las que deberían ser las prioridades estratégicas para la UE en materia de Política Exterior y de Seguridad.

Antes de que Federica Mogherini presentara a la opinión pública su documento, la UE ya había puesto en marcha una serie de instrumentos y tomado medidas para luchar contra el terrorismo. Ahora bien, aunque el trabajo de las fuerzas policiales y autoridades judiciales ha tenido muchos éxitos -como muestra la cantidad de operaciones policiales que han alcanzado sus objetivos y han abortado distintas acciones terroristas-, vistos los ataques sufridos en suelo europeo, cabe cuestionarse la eficacia de las medidas planteadas y ver si, como dice el dicho latino magnus passus extra viam ${ }^{59}$.

Un ejemplo de cooperación internacional sería la puesta en marcha del PNR, que es un acuerdo bilateral relativo al Registro de Nombres de los Pasajeros entre la UE y EEUU, y también con Canadá, Australia y la India. Establece un nuevo sistema de reservas para viajes que contiene todos los datos y eventos relacionados con la misma (nombre del pasajero, fechas de vuelos, itinerarios, asientos, equipaje, información de contacto y medios de pago, nombre del hotel o alquiler de automóvil). Estos datos son proporcionados por los pasajeros a las compañías aéreas. La propuesta de Directiva que se presentó inicialmente a la Comisión trata simplemente de regular la forma en que esos datos son transferidos a las fuerzas de seguridad y cómo las autoridades policiales las usarían para la prevención, detección, investigación y enjuiciamiento de los delitos graves, como el de terrorismo. Finalmente, el Consejo adoptó la Directiva el 21 de abril de 2016 y ahora sólo falta que los Estados Miembros traspongan esta norma en sus respectivos ordenamientos jurídicos nacionales en el plazo máximo de dos años. El acuerdo sobre el PNR se alcanzó no sin dificultades, como

\footnotetext{
${ }^{57}$ Ibid, pp. 1-2.

${ }^{58}$ Ver Díaz Gustavo y Rodríguez, Patricia: "La Unión Europea y el terrorismo islamista”, Revista UNISCI, n 39 (octubre 2015), pp. 184-185.

${ }^{59}$ En efecto, en este tema se han dado grandes pasos, pero fuera del camino correcto. También se puede decir "Magni passus , sed extra víam". Ver Hertenberger, Conrad (1765): Historia pragmatica universalis sacra et profana, Tomo IX. Francfurt/Leipzig, Tobias Göbhardt, p. 230.
} 
reconocen documentos oficiales de la UE, en concreto los que tienen como autor al coordinador de la lucha contra el terrorismo de la UE, el belga Gilles de Kerchove ${ }^{60}$ :

En su resolución de 11 de febrero de 2015 sobre medidas para la lucha contra el terrorismo, el PE se comprometió "a trabajar en pro de la finalización de una directiva de la UE sobre los PNR antes de finales de año", rompiendo así el largo bloqueo de la propuesta. La propuesta de la Comisión relativa al sistema PNR de la UE se presentó en febrero de 2010. El abril de 2012 el Consejo aprobó la orientación general. El ponente del PE presentó su informe el 14 de febrero de 2012, pero la votación en la Comisión LIBE no se produjo hasta el 24 de abril de 2013. Esta votación tuvo como resultado el rechazo de la propuesta de la Comisión por una mayoría de 30 votos en contra y 25 a favor. El 12 de junio de 2013, el Pleno devolvió el expediente a la Comisión LIBE $^{61}$.

Se ha reconocido también que la gestión de fronteras es un asunto difícil de tratar en el seno de la UE. Es positivo que la Comisión haya concluido los indicadores comunes de riesgo. No obstante, subsisten dificultades en relación con la aplicación coordinada, como ya se mencionó en la declaración de París. FRONTEX debe apoyar la plasmación operativa de los indicadores comunes de riesgo y de la aplicación coordinada de controles más sistemáticos por parte de los Estados Miembros. Se podría pedir a FRONTEX que traduzca los indicadores comunes de riesgo en directrices operativas y que las ponga en funcionamiento en los pasos fronterizos oficiales y en el marco de las operaciones conjuntas de FRONTEX, como Poseidón en Grecia y Tritón en Italia, ampliando su ámbito actual para incluir una mayor sensibilización en materia antiterrorista, en particular en lo que se refiere a la detección y a la información voluntaria ${ }^{62}$.

Pero más contundente fue la UE tras los atentados del viernes 13 de noviembre de 2015 en París: Algunos de los autores de los atentados de París realizaron viajes de ida a vuelta a Siria sin ser detectados, lo que demuestra que las medidas tomadas para reforzar los controles en las fronteras exteriores ${ }^{63}$ no son suficientes y es preciso hacer esfuerzos en dos frentes:

- aumentar el número de combatientes terroristas extranjeros (CTE) incluidos en SIS II;

- revisar sistemáticamente las bases de datos de SIS II e Interpol en las fronteras exteriores ${ }^{64}$.

El siguiente párrafo del mismo documento da idea de la complejidad, de la increíble burocracia, de las barreras que hay que saltar para que se llegue a aprobar un documento que reclama medidas "urgentes". Puede que sean documentos muy estudiados, pero que pueden llevar a la desesperación, como se deja entrever en los párrafos que componen este Informe:

Los documentos 9422/1/15 y 12318/15 redactados por el Coordinador de la lucha contra el terrorismo (CLT) de la UE evaluaron el estado de aplicación en junio y octubre de 2015. El documento 12551/15, redactado por la presidencia y el CLT

\footnotetext{
${ }^{60}$ De Kerchove sustituyó en marzo de 2007 a Gijs de Vries al frente de esta responsabilidad, que la había ejercido desde después d delos atentados del 11-M de Madrid.

${ }^{61}$ Ver la Actuación consecutiva a la declaración de los miembros del Consejo Europeo de 12 de febrero de 2015 sobre antiterrorismo: Informe sobre la aplicación de las medidas, 9422/1/15, REV 1, Bruselas, 10 junio 2015 , en http://data.consilium.europa.eu/doc/document/ST-9422-2015-REV-1/es/pdf, p. 2.

${ }_{62}$ Actuación consecutiva a la declaración de los miembros del Consejo Europeo de 12 de febrero de 2015 en materia antiterrorista: situación de la aplicación de las medidas, 12318/15, Bruselas, 5 octubre 2015, en http://data.consilium.europa.eu/doc/document/ST-12318-2015-INIT/es/pdf, p. 2.

${ }^{63}$ Énfasis puesto en el documento original.

${ }^{64}$ Negrita y subrayado del original. Ver Situación de la aplicación de la declaración de los miembros del Consejo Europeo de 12 de febrero de 2015 en materia antiterrorista, 14734/15, Bruselas, 30 noviembre 2015, en http://data.consilium.europa.eu/doc/document/ST-14734-2015-INIT/es/pdf, p. 1.
} 
de la UE, fue aprobado por el Consejo en octubre de 2015. Propone cinco prioridades de acción hasta diciembre de 2015. El debate en el Consejo JAI extraordinario de 20 de noviembre (doc. 14406/15) y en el Comité Permanente de Seguridad Interior (COSI) de 16 de noviembre de 2015 se centró en las armas de fuego $0^{65}$, el refuerzo de los controles fronterizos externos, la puesta en común de la información y la financiación del terrorismo (doc. 14122/15) ${ }^{66}$.

Con anterioridad, Gilles de Kerchove ya había señalado los problemas que Europol ${ }^{67}$ se estaba encontrando a la hora de recabar de los países miembro datos relativos a los llamados "combatientes extranjeros", esto es, europeos que han viajado a Irak y Siria para luchar con el EI:

Los Estados Miembros han venido facilitando cada vez más información sobre los combatientes terroristas extranjeros a Europol desde enero de 2013. El número total de contribuciones es en la actualidad de 1069 (620 a finales de febrero de 2015), con 9724 personas y entidades almacenadas en el Equipo Temático «Viajeros» (3600 en marzo de 2015) [...] Pese a todos estos datos positivos, el Equipo Temático «Viajeros», tanto desde una perspectiva cuantitativa como cualitativa (información fragmentaria), no está aún en disposición de facilitar un análisis complejo y en profundidad en relación con los casos operativos en toda la UE, puesto que más de la mitad de todas las contribuciones procede de cinco Estados Miembros y de un tercer país asociado, tendencia que se mantiene sin cambios. El Equipo Temático «Viajeros» genera entradas basándose en los números de teléfono extranjeros utilizados por los sospechosos en su viaje a Oriente Próximo, también en relación con la facilitación de inmigración ilegal. Esto pone de manifiesto que los Estados Miembros y los países terceros, mediante su contribución al Equipo Temático «Viajeros», pueden beneficiarse de un panorama informativo más amplio ${ }^{68}$.

En su Informe de 4 de marzo de 2016, el coordinador de la lucha contra el terrorismo de la UE señaló los éxitos conseguidos gracias a las medidas puestas en marcha para luchar contra el terrorismo, pero también señaló aspectos concretos que se podrían y deberían mejorar en ese campo ${ }^{69}$. Así pues, los principales instrumentos con los que cuenta la UE en su lucha

\footnotetext{
65 "Las modificaciones, que abordan los riesgos para la seguridad pública, consisten en: mayor control del tráfico de armas de fuego; mejor trazabilidad de las armas de fuego; medidas relativas a la inutilización y la reactivación o transformación de las armas de fuego; condiciones más estrictas para la adquisición y tenencia de las armas de fuego más peligrosas; prohibición del uso civil de las armas de fuego más peligrosas; mejora del intercambio de información pertinente entre los Estados Miembros". Ver "El Consejo acuerda su posición de negociación para reforzar el control de las armas de fuego", Comunicado de prensa 322/16 Asuntos de Interior, 10 Junio 2016, en http://www.consilium.europa.eu/es/press/press-releases/2016/06/10-weapons-strengthen-control/.

${ }^{66}$ Ibid. p. 4.

${ }^{67}$ Europol ha adoptado un nuevo Reglamento interno para adaptarse a la nueva situación. El problema ${ }^{\mathrm{o}} 1$ en la "Lista de formas de delincuencia" que se encuentran entre los objetivos de la organización es, precisamente, el terrorismo. Ver "Reglamento (UE) 2016/794 del Parlamento Europeo y del Consejo de 11 de mayo de 2016 relativo a la Agencia de la Unión Europea para la Cooperación Policial (Europol) y por el que se sustituyen y derogan las Decisiones 2009/371/JAI, 2009/934/JAI, 2009/935/JAI, 2009/936/JAI y 2009/968/JAI del Consejo", en https://www.boe.es/doue/2016/135/L00053-00114.pdf, p. 56.

${ }^{68}$ Ver "Actuación consecutiva a la declaración de los miembros del Consejo Europeo de 12 de febrero de 2015 en materia antiterrorista: situación de la aplicación de las medidas”, 12318/15, Bruselas, 5 octubre 2015, en http://data.consilium.europa.eu/doc/document/ST-12318-2015-INIT/es/pdf, p. 4.

${ }^{69}$ Ver Informe sobre la aplicación de la declaración de los miembros del Consejo Europeo de 12 de febrero de 2015, de las Conclusiones del Consejo JAI de 20 de noviembre de 2015 y de las Conclusiones del Consejo Europeo de 18 de diciembre de 2015, 6785/16, Bruselas, 4 marzo 2016, en http://data.consilium.europa.eu/doc/document/ST-6785-2016-INIT/es/pdf.
} 
contra el terrorismo son ${ }^{70}$ : Europol, Eurojust y FRONTEX. Dentro de Europol se ubicaría el Centro de Lucha contra el Terrorismo (CLTC) ${ }^{71}$, que está dotado de: un equipo temático «Viajeros» (para controlar a los combatientes extranjeros del EI), el TFTP y el TFTS, una Red de Intercambio Seguro de Información (SIENA) ${ }^{72}$, una Unidad de Notificación de Contenidos de Internet de la UE (IRU), una red de unidades de información financiera (FIU.Net). También se contaría con el $\mathrm{PNR}^{73}$ y con los mecanismos puestos en marcha a través de la Decisión Prüm o Tratado de Prüm ${ }^{74}$, sobre cooperación transfronteriza para compartir perfiles de ADN y huellas dactilares. Con Eurojust ${ }^{75}$ se intenta impulsar la cooperación judicial entre Estados Miembros, con procedimientos de extradición más efectivos (como la orden de detención europea y el exhorto europeo de obtención de pruebas), además de colaborar con el Equipo Temático Hydra ${ }^{76}$; el Sistema Europeo de Información de Antecedentes Penales (ECRIS), que permite el intercambio de información sobre antecedentes penales de los ciudadanos de la UE, aunque no funciona eficazmente respecto de los nacionales de terceros países condenados en la UE; el Sistema de información Schengen de segunda generación (SIS

\footnotetext{
${ }^{70}$ Aquí quedan reflejados los que son exclusivamente comunitarios, quedando fuera aquellos que son nacionales o aquellos que se ponen en marcha junto a otras organizaciones internacionales, como la ONU o la OTAN.

${ }^{71}$ El coordinador pide a la Comisión que aumente el presupuesto destinado al CLTL y que los Estados miembros se comprometan más y se esfuercen en cooperar con el Equipo Temático «Viajeros» y a otros Equipos Temáticos de Europol, así como al Sistema de Información de Europol (SIE).

72 “El nivel de confidencialidad de SIENA se elevará a «EU Confidential» en 2016 (se prevé que en el tercer trimestre). Asimismo, está previsto que, en el futuro, la red de comunicación del grupo de trabajo de la policía en materia de terrorismo (PWGT), clasificada como «EU Secret», se integre y esté albergada en Europol, lo que pondrá a disposición de las autoridades dedicadas a la lucha contra el terrorismo de toda la UE una infraestructura de comunicación coherente complementaria”. Ver Informe sobre la aplicación de la declaración de los miembros del Consejo Europeo de 12 de febrero de 2015, de las Conclusiones del Consejo JAI de 20 de noviembre de 2015 y de las Conclusiones del Consejo Europeo de 18 de diciembre de 2015, 6785/16, Bruselas, 4 marzo 2016, en http://data.consilium.europa.eu/doc/document/ST-6785-2016-INIT/es/pdf, p. 14.

${ }^{73}$ El Consejo adoptó la Directiva el 21 de abril de 2016, aunque ahora los Estados tienen dos años para aplicar las disposiciones legales, reglamentarias y administrativas necesarias para dar cumplimiento a lo dispuesto en la Directiva. Ver "El Consejo adopta la Directiva relativa al registro de nombres de los pasajeros (PNR)", Comunicado de prensa 176/16 Asuntos de Interior, 21 abril 2016, en http://www.consilium.europa.eu/es/press/press-releases/2016/04/21-council-adopts-eu-pnr-directive/.

74 "La decisión establece disposiciones sobre: el acceso a ficheros automatizados de análisis de ADN, sistemas automatizados de identificación dactiloscópica y datos de los registros de matriculación de vehículos nacionales; el suministro de datos referentes a grandes acontecimientos; el suministro de información destinada a evitar actos terroristas; otras medidas para reforzar la cooperación policial transfronteriza". Ver la Decisión 2008/615/JAI del Consejo de 23 de junio de 2008 sobre la profundización de la cooperación transfronteriza, en particular en materia de lucha contra el terrorismo y la delincuencia transfronteriza, en http://eur-lex.europa.eu/legalcontent/ES/TXT/HTML/?uri=CELEX:32008D0615\&from=ES.
}

${ }^{75}$ Establecido en 2002 por la Decisión 2002/187/JHA del Consejo, modificada por la Decisión 2009/426/JHA del Consejo, de 16 de diciembre de 2008.

76 "En el Equipo Temático Hydra (sobre terrorismo islamista) del fichero de análisis de Europol en materia de terrorismo, hay actualmente más de 620.000 entidades de datos, incluidas 64.000 entidades «persona» (entre las que se incluyen sospechosos, cómplices, etc., con un incremento de más de 3.500 entidades en 2015) y más de 11.000 entidades relacionadas con organizaciones y redes (lo que supone más de trescientas entidades más que a principios de 2015). Estos datos se actualizan continuamente en colaboración con los socios de Europol y se basan en las más de 12800 aportaciones realizadas hasta la fecha al Equipo Temático Hydra (que han experimentado un incremento del 12\% en 2015). Los Estados Miembros casi han duplicado sus aportaciones al Equipo Temático Hydra entre 2014 y 2015 (pasando de 543 a 1.031), mientras que sus aportaciones sobre individuos casi se han triplicado en el mismo período (pasando de 1.589 a 4.398). Sería aconsejable que los Estados Miembros facilitaran la asociación de Eurojust con el Equipo Temático Hydra para que Eurojust pueda apoyar de forma eficiente y oportuna las investigaciones y actuaciones judiciales en los Estados Miembros". Ver "Informe sobre la aplicación de la declaración de los miembros del Consejo Europeo de 12 de febrero de 2015, de las Conclusiones del Consejo JAI de 20 de noviembre de 2015 y de las Conclusiones del Consejo Europeo de 18 de diciembre de 2015", 6450/16, Bruselas, 1 Marzo 2016, p. 14. 
II), que es el reglamento del antiguo primer pilar ${ }^{77}$; el sistema Eurodac ${ }^{78}$. Por su parte, FRONTEX "debe dar prioridad a detectar en los puntos críticos y otros puntos de entrada de migrantes los pasaportes en blanco que han sido falsificados", mientras que "los Estados Miembros deben enviar más expertos para apoyar a FRONTEX a cotejar la información sistemáticamente en los puntos críticos y para ayudar a Europol en los controles de segunda línea"79. Por otro lado estarían todas las medidas orientadas a controlar los flujos de financiación de los grupos terroristas o de los grupos de delincuencia organizada y la prevención de la utilización del sistema financiero para el blanqueo de capitales. Tras los atentados de Madrid de 2004 se procuró mejorar la seguridad de los explosivos ${ }^{80}$. La UE también cuenta con un Programa europeo para la protección de infraestructuras críticas ${ }^{81} \mathrm{y}$ con un Plan de acción de la UE sobre la seguridad química, biológica, radiológica y nuclear ${ }^{82}$.

Por último, estarían las medidas de control de financiación del terrorismo, como el Terrorist Finance Tracking Programme (TFTP) ${ }^{83}$ y el Terrorist Finance Tracking System (TFTS). Además, la UE trabaja con el Financial Action Task Force (FATF) ${ }^{84}$, que estableció una estrategia para combatir la financiación del terrorismo ${ }^{85}$. En este campo se ha hecho un gran avance en el ámbito internacional, no sólo de la UE, con la creación en cada país de las Unidades de Inteligencia Financiera (FIUs) que han ido generando una estrategia Antilavado de Activos y Lucha contra el Financiamiento del Terrorismo (ALD/LFT) ${ }^{86}$.

\footnotetext{
77 “El SIS II hace más sencillo el intercambio de información entre las autoridades de control de las fronteras nacionales, las autoridades aduaneras y las autoridades policiales sobre las personas que podrían haber participado en un delito grave. También incluye descripciones de personas desaparecidas, especialmente de niños, e información sobre determinados bienes, tales como billetes de banco, automóviles, camionetas, armas de fuego y documentos de identidad robados, sustraídos o extraviados". Ver "El Sistema de Información de Schengen (SIS II) empieza a funcionar", Bruselas, 9 Abril 2013, en http://europa.eu/rapid/press-release IP-13309 es.htm.

${ }^{78}$ Es un sistema de comparación de las impresiones dactilares de los solicitantes de asilo y algunas categorías de inmigrantes irregulares. Está pensado para que facilite la aplicación del Reglamento Dublín II, que permite determinar qué país de la Unión Europea (UE) es responsable del examen de una solicitud de asilo. Ver Reglamento (CE) $n^{\circ}$ 2725/2000 del Consejo, de 11 de diciembre del 2000, relativo a la creación del sistema «Eurodac» para la comparación de las impresiones dactilares para la aplicación efectiva del Convenio de Dublin, en http://eur-lex.europa.eu/legal-content/ES/TXT/HTML/?uri=CELEX:32000R2725\&from=ES.

${ }^{79}$ Ver "Informe sobre la aplicación de la declaración de los miembros del Consejo Europeo de 12 de febrero de 2015, de las Conclusiones del Consejo JAI de 20 de noviembre de 2015 y de las Conclusiones del Consejo Europeo de 18 de diciembre de 2015”, 6785/16, Bruselas, 4 marzo 2016, en http://data.consilium.europa.eu/doc/document/ST-6785-2016-INIT/es/pdf, p. 3.

${ }^{80}$ Comunicación de la Comisión, de 18 de julio de 2005, relativa a las medidas para garantizar una mayor seguridad en el control de los explosivos, detonadores, material para la fabricación de bombas y armas de fuego [COM (2005) 329 final, en http://eur-lex.europa.eu/legalcontent/ES/TXT/HTML/?uri=CELEX:52005DC0329\&from=ES.

${ }^{81}$ Ver Comunicación de la Comisión de 12 de diciembre de 2006 sobre un Programa Europeo para la Protección de Infraestructuras Críticas, COM (2006) 786 final, 12 diciembre 2006, en http://eurlex.europa.eu/legal-content/ES/TXT/PDF/?uri=CELEX:52006DC0786\&from=ES.

${ }^{82}$ Ver Comunicación de la Comisión al Parlamento Europeo y al Consejo, de 24 de junio de 2009, sobre el refuerzo de la seguridad química, biológica, radiológica y nuclear en la Unión Europea, en http://eurlex.europa.eu/legal-content/ES/TXT/?uri=uriserv\%3Aj10030.

${ }^{83}$ Es un acuerdo entre los EE.UU. y la UE para compartir información en lo relativo a la financiación del terrorismo.

${ }^{84}$ También conocida por su nombre en francés: Groupe d'action financière sur le blanchiment de capitaux (GAFI). Fue establecido por el G8 en 1989.

${ }^{85}$ FATF: Consolidated FATF Strategy on Combatting Terrorist Financing, en http://www.fatfgafi.org/media/fatf/documents/reports/FATF-Terrorist-Financing-Strategy.pdf.

${ }^{86}$ Gleason, Paul y Gottselig, Glenn (2004): Unidades de Inteligencia Financiera: Panorama General. Washington, Fondo Monetario Internacional. Traducido al español por Adriana Russo y Carlos Viel. Ver también Schott, Paul Allan (2006): Guía de referencia para el antilavado de activos y la lucha contra el financiamiento del terrorismo, $2^{\mathrm{a}}$ ed. Bogotá, Banco Mundial.
} 
En este campo, gracias a las investigaciones policiales y judiciales, se intenta seguir mejor el recorrido del dinero que acaba utilizándose para financiar a los grupos terroristas. Se citan como métodos tradicionales de financiación donaciones privadas, el uso indebido de ONGs, ingresos provenientes de actividades criminales, extorsión a la población y a los empresarios locales y a los que han huido, rescates por secuestro, negocios legales que son pantalla para la financiación, explotación de recursos naturales (especialmente gas, petróleo y productos mineros) y subvenciones estatales (que acaban voluntaria o involuntariamente en los bolsillos de los terroristas) $)^{87}$.

Por su parte, en el día europeo de las víctimas del terrorismo (11 de marzo) de 2016, se celebró un Consejo de Justicia y Asuntos de Interior en el que se aprobó una Orientación general Directiva relativa a la lucha contra el terrorismo. En ella, recuerda cuál es el fundamento jurídico básico para la lucha contra el terrorismo ${ }^{88}$ y reclama que se penalice el hecho de viajar con fines terroristas -para disuadir a los futuros retornados- y recibir adiestramiento con fines terroristas; por supuesto, también se hace hincapié en perseguir con mayor eficacia la financiación o el apoyo logístico y material a estos grupos. Se introduce un nuevo tipo penal que es el de "provocación a la comisión de delitos terroristas" 89 , que aún debe ser definido y ser llevado a las legislaciones nacionales: "A fin de reforzar las medidas contra la provocación de comisión de delitos terroristas, y teniendo en cuenta el uso cada vez más extendido de la tecnología, sobre todo de Internet, parece procedente que los Estados Miembros adopten medidas para eliminar o bloquear el acceso a páginas web que induzcan públicamente a la comisión de delitos terroristas. Cuando se adopten tales medidas, deben establecerse mediante procedimientos transparentes y ofrecer las garantías adecuadas, en particular para garantizar que las restricciones se limiten a lo necesario y sean proporcionadas." 90

\footnotetext{
${ }^{87}$ Ver FATF: Emerging Terrorist Financing Risks, Octubre 2015, en http://www.fatfgafi.org/media/fatf/documents/reports/Emerging-Terrorist-Financing-Risks.pdf
}

${ }^{88}$ Principalmente, la Decisión Marco del Consejo, de 13 de junio de 2002, sobre la lucha contra el terrorismo (DO L 164 de 22.6.2002, p. 3), más conocida como Decisión Marco 2002/475/JAI del Consejo y que da una definición armonizada de los delitos de terrorismo y sirve como base para el intercambio de información y la cooperación entre las autoridades nacionales competentes en virtud de la Decisión Marco 2006/960/JAI del Consejo o Decisión Marco 2006/960/JAI del Consejo, de 18 de diciembre de 2006, sobre la simplificación del intercambio de información e inteligencia entre los servicios de seguridad de los Estados Miembros de la Unión Europea (DO L 386 de 29.12.2006, p. 89). Por otro lado, estaría la Decisión 2008/615/JAI del Consejo, de 23 de junio de 2008, sobre la profundización de la cooperación transfronteriza, en particular en materia de lucha contra el terrorismo y la delincuencia transfronteriza (DO L 210 de 6.8.2008, p. 1) y la Decisión 2005/671/JAI del Consejo, de 20 de septiembre de 2005, relativa al intercambio de información y a la cooperación sobre delitos de terrorismo (DO L 253 de 29.9.2005, p. 22). Por el Reglamento (UE) n ${ }^{\circ} 603 / 2013$ del Parlamento Europeo y del Consejo, de 26 de junio de 2013, se creó la "Eurodac". La Decisión Marco 2002/584/JAI del Consejo, de 13 de junio de 2002, es relativa a la orden de detención europea y a los procedimientos de entrega entre Estados Miembros (DO L 190 de 18.7.2002, p. 1) y la Decisión Marco 2002/465/JAI del Consejo, de 13 de junio de 2002, versa sobre equipos conjuntos de investigación (DO L 162 de 20.6.2002, p. 1).

${ }^{89}$ En realidad, no es tan nuevo, pues ya hablaba de él el art. 3 de la Decisión Marco 2008/919/JAI del Consejo, 28 de noviembre de 2008, en http://eur-lex.europa.eu/legalcontent/ES/TXT/HTML/?uri=CELEX:32008F0919\&from=ES.

${ }^{90}$ Ver "Propuesta de Directiva del Parlamento Europeo y del Consejo relativa a la lucha contra el terrorismo, y por la que se sustituye la Decisión Marco 2002/475/JAI del Consejo sobre la lucha contra el terrorismo [primera lectura] - Orientación general", 6655/16, Bruselas, 3 de marzo de 2016, p. 5. En cuanto a esta "provocación", hay que tener en cuenta los límites de la aplicación de este nuevo concepto: "20 bis: Nada de lo dispuesto en la presente Directiva podrá interpretarse como un intento de reducir u obstaculizar la difusión de información con fines científicos, académicos o informativos. La expresión pública de opiniones radicales, polémicas o controvertidas sobre cuestiones políticas delicadas queda fuera del ámbito de aplicación de la presente Directiva y, en especial, de la definición de provocación a la comisión de delitos de terrorismo". Ibídem, p. 11. 
Por otro lado, las autoridades europeas están preocupadas por los terroristas que actúan en suelo europeo y por aquellos jóvenes que abandonan su casa para ir a campos especiales de entrenamiento e integrarse así en un grupo terrorista, pero también por los europeos que abandonan el territorio de la UE para marcharse a luchar en Irak y Siria.

Para frenar estos flujos de combatientes, el Consejo propuso entrar en la batalla de las ideas, para "ganar las mentes y los corazones":

"En particular, deberíamos plantearnos el objetivo de ofrecer salidas alternativas no violentas, tales como actividades de distracción para los que se sienten atraídos por los conflictos de Siria e Irak. Existe una inmensa variedad de material que deberíamos explotar para elaborar un discurso alternativo, en nuestra labor tanto interna como externa, para contradecir los discursos terroristas y su supuesta ideología". ${ }^{91}$

Estas Líneas generales también hacen hincapié en que el fenómeno del terrorismo es mucho más amplio y para comprenderlo completamente no se puede reducir al ámbito policial y hay que tener en cuenta "procesos políticos más amplios". ${ }^{92}$

Ahora bien, de poco sirven este tipo de medidas si al final del proceso hay un juez que, contra la opinión del fiscal, pone en libertad bajo fianza y controlada -por pulsera electrónicaa un individuo que ha sido detenido en Turquía ${ }^{93}$ por intentar viajar a Siria, ha sido devuelto a Francia, juzgado y condenado. Si al final dicho individuo degüella a un sacerdote octogenario en Francia, ¿a quién se le puede exigir responsabilidades? ${ }^{94}$ En la lucha del Estado de Derecho contra el terrorismo es necesario evitar las "grietas" y las faltas de coordinación entre las partes implicadas con el fin de evitar tragedias..$^{95}$

Por último, se puede señalar que entre la Estrategia Europea de Seguridad de 2003 y la Estrategia Global para la Política Exterior y de Seguridad de la UE (2016) hay algunas diferencias. Esto se debe, sobre todo, a que la UE había evolucionado hacia una mayor cohesión al pasar por la crisis institucional tras la fallida aprobación de la Constitución para Europa y su remedo del Tratado de Lisboa; la crisis económica pasó factura también a la UE por haber optado por la ampliación antes que por la profundización. Su relación con el vecindario también ha variado, sobre todo tras la irrupción de las primaveras árabes. La intervención en Irak (2003) no fue el único conflicto violento en el entorno europeo (Osetia del Sur, primaveras árabes, Libia, Siria, Ucrania,...) que ahondó la división entre los Estados

\footnotetext{
${ }^{91}$ Ver Lineas generales de la estrategia antiterrorista para Siria e Irak, con particular atención a los combatientes extranjeros, 5369/15, Bruselas, 16 de enero de 2015, en http://data.consilium.europa.eu/doc/document/ST-5369-2015-INIT/es/pdf, p. 4. ${ }^{92}$ Ibíd. p. 2.

${ }^{93}$ Como es sabido, Turquía tampoco está libre del azote del terrorismo. Sufre los ataques del PKK pero también del Estado Islámico. Ver Villalón, Lara: “Al menos 50 muertos en un atentado perpetrado por un adolescente en un salón de bodas en Turquía”, El Mundo, 21 agosto 2016, en http://www.elmundo.es/internacional/2016/08/21/57b8d87ee2704ee8688b459d.html.

94 “Trató de viajar a Siria el 15 de mayo del año pasado, pero fue devuelto por las autoridades turcas. Este individuo, según la misma fuente, fue procesado en Francia a su regreso por el delito de asociación terrorista. El pasado 22 de marzo, salió en libertad condicional, en un horario limitado de 8.30 a 12.30 de la mañana, pero controlado con una pulsera electrónica. La Fiscalía recurrió sin éxito la decisión del juez de sacarlo de la prisión preventiva". Ver Martín, Isaac J.: "Un cura degollado y una rehén en estado crítico en una ataque del IS en una iglesia de Normandía", El Mundo, 26 julio 2016, en http://www.elmundo.es/internacional/2016/07/26/5797245a46163f54238b4597.html.

${ }^{95}$ Ver Escrivá, Ángeles: "Jueces detectan descoordinación en operaciones antiterroristas", El Mundo, 17 agosto 2016, en http://www.elmundo.es/espana/2016/08/17/57b36ba822601d7f488b45ee.html.
} 
Miembros y puso en evidencia la inoperancia de una Política Exterior común que en realidad no existe. Además, con la llegada de Obama al poder, EE.UU no ha dado prioridad a los asuntos europeos, centrándose en otros puntos de su propio interés nacional. En el caso del terrorismo, ha sido evidente, además, que se ha ido a remolque de las situaciones con las que las autoridades se han ido encontrando; esto es, es una política muy reactiva, como el incremento de controles en medios de transporte al hilo de ataques terroristas perpetrados en aviones, autobuses y trenes ${ }^{96}$.

\section{Las líneas maestras de la nueva Estrategia de 2016.}

El marco general de la Estrategia de 2016 parte del presupuesto de que la UE deja de aspirar a ser un líder global ${ }^{97}$ y se centra en su tarea de ser un líder regional con un vecindario "complicado". De hecho, aunque el documento lleve el adjetivo "global" en el título la misma Mogherini explicó que con ello se refería a los medios que se utilizarán para poner en marcha dicha Estrategia; en pocas palabras, "global" aquí es sinónimo de "comprehensive approach" 98 . En relación con esto, hay un momento en el que reconoce que la UE por sí sola no puede luchar contra el terrorismo, que necesita otros apoyos.

La Estrategia de 2016 tiene un párrafo extenso dedicado exclusivamente al contraterrorismo; lo trata como una de las cinco líneas de acción de la Seguridad de la Unión (punto 3.1), que es una de las Prioridades de la Acción Exterior de la UE. Aparte de dicho párrafo, la cuestión del terrorismo está diseminada por todo el documento pues afecta a la relación con países del entorno, con la ONU y está vinculado con el crimen organizado y la proliferación de ADM. El documento resulta bastante desordenado.

El párrafo de la página 21, al que se acaba de aludir, expone las bases sobre las que se debe asentar la lucha contra el terrorismo según la UE. Le dedica especial atención a la

\footnotetext{
${ }^{96}$ Esto sucedió, por ejemplo, después de los atentados del 11-S y también después del atentado terrorista frustrado en el tren Thalys que unía Ámsterdam con París, en agosto de 2015. Ver "Francia espera que los ministros de Interior europeos aprueben este sábado "más controles" en estaciones y aeropuertos", RTVE, 26 agosto 2015, en http://www.rtve.es/noticias/20150826/francia-espera-ministros-interior-europeos-aprueben-estesabado-mas-controles-estaciones-aeropuertos/1206361.shtml. Ver también Teruel, Ana: "El autor del atentado contra el tren Ámsterdam- París vivió en Algeciras", El País, 24 agosto 2015, en http://internacional.elpais.com/internacional/2015/08/21/actualidad/1440180926 977511.html.

${ }_{97}$ Antes de pasar al análisis de la Estrategia de 2016, es necesario señalar que Francia y Alemania publicaron un documento conjunto titulado A strong Europe in a world of uncertainties, que era una especie de anticipo de lo que sería la Estrategia Global para la Política Exterior y de Seguridad de la UE (2016). En el susodicho documento franco-alemán, se deja claro que el sustento de la Estrategia de 2016 pasa por el acuerdo entre esos dos países; dicho con otras palabras, el corazón de la UE está compuesto por esos dos países. Hay que subrayar que esta declaración conjunta se hizo justo después del referéndum sobre el Brexit. Uno de los temas en los que ponen de manifiesto que su cooperación es esencial: "In order to address the root causes of terrorism, France and Germany will develop a European platform to share experience and best practice in preventing and counteracting radicalization". Ver Ayrault, Jean-Marc y Steinmeier, Frank-Walter: "A strong Europe in a world of uncertainties", en http://www.diplomatie.gouv.fr/en/french-foreign-policy/european-union/events/article/astrong-europe-in-a-world-of-uncertainties-28-06-16, p. 3.

${ }^{98}$ Sobre el enfoque comprehensivo, ver lo que dice el documento realizado por diversos think tanks europeos antes de la publicación de la Estrategia de 2016: "By working with both state and non-state partners in the region, the EU should therefore upgrade its efforts to combat international terrorism, the proliferation of weapons of mass destruction, organized crime and the trafficking of arms, drugs and human beings. Local capacity-building measures, including security-sector reform, would facilitate cooperation with the EU on policing, intelligence sharing, border management and civil protection as well as on judicial matters". Como se ve, el tratamiento del terrorismo en este documento es bastante deficiente. Ver "EGS Towards a European Global Strategy", 28 mayo 2013, en http://www.realinstitutoelcano.org/wps/wcm/connect/4c2675804fc8b86b80b5caccba746acc/EGS_Report.pdf?M

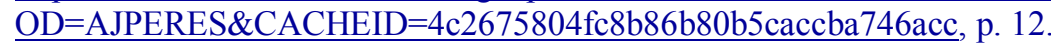


cooperación entre Estados -especialmente en materia de inteligencia, lo cual es más un deseo que una posibilidad real ${ }^{99}$-. Señala, eso sí, algunos puntos clave sobre información que sí se puede compartir: alertas sobre extremismo violento, redes terroristas y combatientes extranjeros ${ }^{100}$. Aparte de estas categorías, podría haber incluido a los denominados retornados, terroristas que han viajado al campo de batalla para recibir entrenamiento sobre un terreno de guerra real y que vuelven a casa con amplios conocimientos en manejo de explosivos y en tácticas de guerrilla urbana.

También se señala en dicho párrafo el papel de los Estados a la hora de controlar el contenido de la red y de los demás medios de comunicación. Esa tarea de censura es realmente difícil; en los medios, porque existe la libertad de expresión y la de información y ahora hay abierto un debate acerca de los límites de las mismas, sobre si debe prevalecer sobre la seguridad ${ }^{101}$, o si mostrar ciertas imágenes o revelar detalles de cómo acabaron las víctimas es provechoso para la información o sirven como instrumento de propaganda para las atrocidades cometidas por los terroristas, lo que incrementa su potencial de generar alarma o terror $^{102}$. Por otro lado, los terroristas usan casi impunemente internet y las redes sociales, que son un gran apoyo para el reclutamiento, y eso debería estar más controlado ${ }^{103}$.

\footnotetext{
${ }^{99}$ Aunque se ha instituido un Centro de Análisis de Inteligencia de la UE (INTCEN), hay analistas que tienen una visión más optimista sobre este tema y hablan de un proceso de integración "que va a durar años". De hecho, este INTCENT se llamó desde sus orígenes (1999) hasta 2012 EU Situation Centre (EU SITCEN). Ver Albaladejo, Javier: "Hacia un nuevo modelo de intercambio de información frente a las amenazas para la seguridad interior de la UE y sus Estados Miembros", Comentario Elcano, 35/2016, 13 julio 2016, en http://www.realinstitutoelcano.org/wps/portal/web/rielcano es/contenido?WCM GLOBAL CONTEXT=/elcan o/elcano es/zonas es/comentario-albaladejo-hacia-nuevo-modelo-intercambio-informacionue?utm source=Newsletter193\&utm medium=email\&utm campaign=Jul2016.

100 "Under the new programme "Countering radicalisation and Foreign Terrorist Fighters", the EU will allocate a first tranche of $€ 5$ million to fund technical assistance to enhance the capacities of criminal justice officials to investigate, prosecute and adjudicate cases of foreign fighters or would-be foreign fighters. The second tranche of 5 million euro will finance countering radicalisation programmes in the Sahel and Maghreb region. It will offer the possibility to non-state actors to implement activities in the field of media, education, religion, culture. Projects focussing on messaging, internet, social media, disengagement, and awareness-raising with social workers will also be considered as well as measures preventing the radicalisation and recruitment of foreign fighters". Ver "EU provides $€ 10$ million to counter radicalisation in the Sahel-Maghreb and stem the flow of foreign fighters from North Africa, the Middle East and Western Balkans", European Commission - Press release, 28 abril 2015, en http://europa.eu/rapid/press-release IP-15-4866 en.htm.

${ }^{101}$ Los terroristas pueden mejorar su forma de actuar en un futuro gracias a que informaciones periodísticas revelan cuáles han sido los errores cometidos por los terroristas que ya han actuado, es relativamente de fácil acceso al público general conocer cómo se han desarrollado las investigaciones y ver qué pistas se han seguido. ${ }^{102}$ No se revelaron ciertos detalles sobre lo que hicieron los terroristas en la sala Bataclan de París, detalles que incrementan la imagen de barbarie de los terroristas pero que añaden cualitativamente poco a la valoración general de aquel acto en sí (era repudiable de todas formas, conociendo esos detalles o no). Ver el informe realizado por Sébastien Pietrasanta para la comisión parlamentaria de investigación presidida por Georges Fenech: Rapport Fait au nom de la commission D'enquête relative aux moyens mis en oeuvre par l'État pour lutter contre le terrorisme depuis le 7 janvier 2015 en http://www.ladocumentationfrancaise.fr/rapportspublics/164000560/index.shtml

${ }^{103}$ Para ser ecuánimes, hay que reconocer que la inmensa mayoría de las detenciones realizadas en España contra células yihadistas se refieren, precisamente, a detenciones de reclutadores de futuros combatientes o reclutadoras de futuras esposas de "muyahidines". Las operaciones policiales en otros países europeos tienen esa misma característica. Hay que decir que las fuerzas de seguridad son plenamente conscientes de que el papel del reclutador es fundamental y por eso le dedican gran atención y bastantes recursos. Ver GESI: “Operaciones policiales contra el terrorismo yihadista en España", en http://www.seguridadinternacional.es/?q=es/content/operaciones-policiales-contra-el-terrorismo-yihadista-enespa\%C3\%B1. Ver también Ortega Dolz, Patricia: "Un detenido en Palma de Mallorca por reclutar combatientes del ISIS", El País, 19 Abril 2016, en http://politica.elpais.com/politica/2016/04/19/actualidad/1461045530 395003.html.
} 
Por último, dentro de ese párrafo, toca el punto fundamental de la lucha contra el terrorismo, que no es tanto la financiación -punto que también señala esta Estrategia ${ }^{104}$ - como el problema cultural y educativo que hay de fondo. Las personas que han dado el paso a la violencia terrorista en general y la yihadista en particular, son personas que no han asimilado los valores europeos. Sin embargo, según la Estrategia de 2016 estos valores brillan por sí solos y tienen un poder casi irresistible de atracción para los países de todo el mundo ${ }^{105}$, y por eso desean entablar relaciones con nosotros. Más bien no; sólo desean nuestra prosperidad económica, nuestro bienestar social, pero no quieren oír hablar de nuestros valores ${ }^{106}$. De hecho, el documento habla de "principled pragmatism", un pragmatismo con principios, poniendo el acento, claro está, no en los principios sino en el pragmatismo. No obstante, su apuesta por la lucha contra la radicalización es acertada, fomentando una educación que vaya orientada a frenar el avance de esas ideas; el punto negativo es que, de nuevo, yerra en el cómo, ya que apuesta por el diálogo inter-religioso e inter-cultural ${ }^{107}$. No es que el diálogo entre religiones o culturas no sea eficaz, sino que hasta ahora se ha hecho sobre una premisa errónea: los valores que actualmente imperan en el discurso europeo políticamente correcto son absolutamente superiores a los del resto del mundo, o al menos hay una serie de valores innegociables, entre los que estaría la igualdad de género ${ }^{108}$. Pero la percepción de que se ofrece materialismo y hedonismo como vía de solución a personas que están en búsqueda de fundamentos sólidos para su vida ${ }^{109}$, no parece lo más eficaz para la lucha contra el terrorismo, como llega a afirmar más adelante el documento: "Solving conflicts and promoting

\footnotetext{
${ }^{104}$ Hay que reconocer que las medidas tomadas por las autoridades comunitarias para frenar la financiación del terrorismo son bastante más eficaces y mucho más preventivas que otras medidas que se toman en este campo. "La UE puede ayudar también apoyando los esfuerzos realizados por los socios para combatir los delitos graves, como el tráfico de drogas o de armas de fuego, como fuente de financiación del terrorismo". Ver "Comunicación de la Comisión al Parlamento Europeo y al Consejo. Plan de acción para intensificar la lucha contra la financiación del terrorismo", COM (2016) 50 final, Estrasburgo, 2 Febrero 2016, en http://data.consilium.europa.eu/doc/document/ST-5782-2016-INIT/es/pdf, p. 16.

105 "To engage responsibly with the world, credibility is essential. The EU's credibility hinges on our unity, on our many achievements, our enduring power of attraction, the effectiveness and consistency of our policies, and adherence to our values", Estrategia Global para la Política Exterior y de Seguridad de la UE (2016), p. 44. ${ }^{106}$ En ese sentido, el Ministro del Interior francés, Bernard Cazeneuven, anunció en verano de 2016 la creación de una Fundación para el Islam de Francia con el objetivo de adaptar el Islam a la laicidad francesa ya los valores republicanos: "Esto supone también que todos los musulmanes franceses se comprometan en una defensa total de los valores de la República frente al terrorismo y el salafismo. La adhesión a los valores republicanos debe trascender todo lo demás". Ver Valderrama, María: "Francia quiere crear un Islam propio "moderno, fuerte y tranquilo"', El Mundo, 29 Agosto 2016, en http://www.elmundo.es/internacional/2016/08/29/57c45c2aca474183798b45d5.html.

${ }^{107}$ La Alianza de Civilizaciones - como programa de la ONU - parece ya descartada, mas no su filosofía, que es la que impregna este documento, que en definitiva es un interés por laicizar el espacio público global, anular el fenómeno religioso en la vía pública y dejarlo arrinconado a la conciencia o a reducido a mera manifestación cultural o tradicional, pero que no afecte a la vida ordinaria de las personas ni a la forma en que se estructuran las sociedades o se establecen los sistemas sociales.

${ }^{108}$ La igualdad entre hombres y mujeres, defendida como "igualdad de género", es una de las puntas de lanza de la llamada "ideología de género", que afirma que no existe el sexo biológico sino que cada cual puede definir su "identidad de género".

${ }^{109}$ Ver el estudio de Reinares, Fernando y García-Calvo, Carola (2016): Estado Islámico en España, Real Instituto Elcano, pp. 50-57. En especial "La principal de las motivaciones individuales para la implicación en actividades terroristas relacionadas con EI es, en el caso de los detenidos en España desde 2013, de índole ideológica y utilitaria. Menos frecuente es que predomine una de naturaleza emocional y afectiva o, por último, una existencial e identitaria. Sin embargo estos tres tipos de motivaciones individuales pueden combinarse de forma variable para cada individuo según sus características sociales y circunstancias personales". Ibíd. p. 56. En cuanto a las motivaciones relacionadas de alguna manera con la religión, el experto William McCants, de la Brooking Institution, señala la importancia, el poder de atracción de una doble idea: la profecía del advenimiento del final del mundo y la construcción de un califato. Ver McCants, William (2015): The ISIS Apocalypse: The History, Strategy, and Doomsday Vision of the Islamic State. Nueva York, St. Martin's Press.
} 
development and human rights in the south is essential to addressing the threat of terrorism" $" 110$.

A pesar de esto, afirma más adelante que ese poder de atracción no es suficiente y que se necesita el compromiso de los Estados Miembros para poner en marcha las medidas adoptadas en el seno de la Unión -especialmente las relativas a custodia de explosivos y control de armas de fuego ${ }^{111}$ y el PNR $^{112}$ - y llama a la cooperación con otros Estados y organizaciones internacionales, citando a la OTAN, apoyando el uso de medios militares para la lucha contra el terrorismo y llamando a que se incrementen los presupuestos nacionales en Defensa $^{113}$. También a la Unión por el Mediterráneo ${ }^{114}$-organización que quedó desactivada en la práctica por el efecto de las primaveras árabes desde 2011 -

Siguiendo con esta última cuestión, también hace una gran apuesta por la cooperación con una parte de la sociedad civil para fomentar una educación que frene la radicalización ${ }^{115}$. En concreto, habla de resiliencia de la sociedad ${ }^{116}$. Además, se ha puesto en marcha una red de expertos sobre radicalización y un centro de excelencia: "La Red para la Sensibilización frente a la Radicalización (RSR), un marco a escala de la UE que se puso en marcha en 2011, conecta a organizaciones y redes de toda la Unión, uniendo a más de 1000 profesionales directamente implicados en la prevención de la radicalización y el extremismo violento" $" 117$.

${ }^{110}$ Estrategia Global para la Política Exterior y de Seguridad de la UE (2016), p. 34.

${ }^{111}$ Ya en la Agenda Europea de Seguridad de 2015 se denunciaba que: "Los recientes atentados terroristas han centrado la atención en cómo la delincuencia organizada puede acceder y comerciar con armas de fuego en Europa, incluso armas militares, en grandes cantidades. La decisión de quién puede estar en posesión de un arma de fuego y cuándo se puede utilizar es una opción de las sociedades de los Estados miembros. No obstante, las diferencias en las legislaciones nacionales constituyen un obstáculo a los controles y la cooperación policial". Ver Comunicación de la Comisión al Parlamento Europeo, al Consejo, al Comité Económico y Social Europeo y al Comité de las Regiones. Agenda Europea de Seguridad, COM (2015) 185 final, Estrasburgo, 28 Abril 2015, en http://eur-lex.europa.eu/legal-content/ES/TXT/PDF/?uri=CELEX:52015DC0185\&from=ES, p. 20.

112 Estrategia Global para la Política Exterior y de Seguridad de la UE (2016), p. 45.

113 "In this fragile world, soft power is not enough: we must enhance our credibility in security and defence. To respond to external crises, build our partners' capacities and protect Europe, Member States must channel a sufficient level of expenditure to defence". Ver Estrategia Global para la Politica Exterior y de Seguridad de la UE (2016), p. 44.

114 "We will back practical cooperation, including through the Union for the Mediterranean, on issues such as border security, trafficking, counter-terrorism, nonproliferation". Ver Estrategia Global para la Política Exterior $y$ de Seguridad de la UE (2016), p. 34.

115 "On counterterrorism, we will deepen dialogue with the UN, while building broad partnerships with states, regional organisations, civil society and the private sector on issues such as countering violent extremism and terrorist financing". Ver Estrategia Global para la Política Exterior y de Seguridad de la UE (2016), pp. 43-44.

116 "We will nurture societal resilience also by deepening work on education, culture and youth to foster pluralism, coexistence and respect”. Estrategia Global para la Política Exterior y de Seguridad de la UE (2016), p. 27.

${ }^{117}$ Ver "Comunicación de la Comisión al Parlamento Europeo, al Consejo, al Comité Económico y Social Europeo y al Comité de las Regiones. Agenda Europea de Seguridad”, COM (2015) 185 final, Estrasburgo, 28 abril 2015, en http://eur-lex.europa.eu/legal-content/ES/TXT/PDF/?uri=CELEX:52015DC0185\&from=ES, p. 18. "El Centro de Excelencia de la Red para la Sensibilización frente a la Radicalización constituye el polo y la plataforma europeos para el intercambio de experiencias, la puesta en común de conocimientos, la identificación de las mejores prácticas y el desarrollo de nuevas iniciativas en la lucha contra la radicalización. Cuenta con distintos intervinientes (psicólogos, educadores, trabajadores sociales, líderes comunitarios, ONG, etc., además de policías, funcionarios de prisiones, agentes responsables de la libertad condicional y representantes de distintos ministerios y administraciones) en todas las áreas pertinentes, que van desde la mejora de la resiliencia frente a la propaganda extremista en internet hasta la radicalización en los centros penitenciarios y el entorno educativo, y presta una atención especial a los jóvenes". Ver "Comunicación de la Comisión al Parlamento Europeo, al Consejo, al Comité Económico y Social Europeo y al Comité de las Regiones. Apoyo a la prevención de la radicalización que conduce al extremismo violento”, COM (2016) 379 final, Bruselas, 14 Junio 
Esto entronca con toda una cultura de seguridad basada en la comunidad ${ }^{118}$. Esta apuesta ha tenido sus logros pero también sonoros fracasos. Entre los experimentos exitosos están aquellos think tanks o fundaciones independientes dedicadas a realizar estudios sobre la radicalización y la desradicalización, que cuentan entre sus filas, precisamente, con personas que han sufrido ambos procesos de ida y vuelta ${ }^{119}$. En ese sentido, se introducirían las medidas denominadas RAN (Radicalisation Awareness Network) ${ }^{120}$ y sus diversos RAN Working Groups que puso en marcha la Dirección General de Migración y Asuntos de Interior, en el seno de la Comisión. Otro de los puntos fuertes de esta apuesta por el trabajo con las comunidades de base es la creencia de que un terrorismo sin base social, sin apoyo más allá de las personas involucradas directamente en la comisión de actos terroristas, tiene los días contados, está abocado a la desaparición; dicho de otro modo, sin legitimidad social no hay grupo terrorista que aguante muchos años ${ }^{121}$.

Por último, la Estrategia de 2016 señala acertadamente el vínculo que existe entre seguridad interior y exterior en cuanto a este tema del terrorismo ${ }^{122}$. Por eso, recuerda que hay tres organismos que trabajan sobre este tema, como se verá a continuación, que son Europol, Eurojust y Frontex. No obstante, no hace mención alguna a la Estrategia de Seguridad Interior de la UE (2010) ni a otros documentos similares ${ }^{123}$ que hacen hincapié en la lucha contra este fenómeno desde el interior de la Unión, desde los Estados Miembros ${ }^{124}$.

2016, en http://eur-lex.europa.eu/legalcontent/ES/TXT/PDF/?uri=CELEX:52016DC0379\&qid=1469830069608\&from=ES, p. 5.

${ }^{118}$ Ver Spalek, Basia (ed) (2012): Counter-Terrorism Community-Based Approaches to Preventing Terror Crime. Nueva York, Palgrave Macmillan.Ver también Terrorism and Community Relations, House of Commons, Home Affairs Committee, 14 diciembre 2004, en http://www.publications.parliament.uk.

${ }^{119}$ Sería el caso británico de la Quilliam Foundation y sus fundadores Maajid Nawaz, Rashad Zaman Ali and Ed Husain.

${ }^{120}$ Ver "Radicalisation Awareness Network (RAN)", en http://ec.europa.eu/dgs/home-affairs/what-wedo/networks/radicalisation awareness network/index en.htm.

${ }^{121}$ Ver Weinberg, Leonard y Pedahzur, Ami (2003): Political Parties and Terrorist Groups. Londres, Routledge. En España, el Ministerio de Justicia puso en marcha en octubre de 2004 la Fundación Pluralismo y Convivencia precisamente para frenar el ascenso de la islamofobia que podría generarse tras el 11-S y los atentados de Madrid de marzo de 2004; su objetivo es trabajar con las comunidades religiosas directamente y a través de las grandes Federaciones religiosas, en este caso con las mezquitas y la Comisión Islámica de España. Ante cualquier atentado, estos actores han negado categóricamente que eso tenga algo que ver con el islam y que esta es una religión de paz; este es el punto nodal de la prevención del terrorismo yihadista, como se verá más adelante, y ha encendido un debate muy vivo con posturas muy encontradas entre los islamólogos

122 "In security terms, terrorism, hybrid threats and organised crime know no borders. This calls for tighter institutional links between our external action and the internal area of freedom, security and justice. Closer ties will be fostered through joint Council meetings and joint task forces between the EEAS and the Commission. Defence policy also needs to be better linked to policies covering the internal market, industry and space. Member State efforts should also be more joined-up: cooperation between our law enforcement, judicial and intelligence services must be strengthened. We must use the full potential of Europol and Eurojust, and provide greater support for the EU Intelligence Centre. We must feed and coordinate intelligence extracted from European databases, and put ICT - including big data analysis - at the service of deeper situational awareness. Our citizens need better protection also in third countries through joint contingency plans and crisis response exercises between Member States". Ver la Estrategia Global para la Política Exterior y de Seguridad de la UE (2016), p. 50. Este vínculo ya había sido puesto de manifiesto en un documento de finales de 2010: "La seguridad interior no puede lograrse de forma aislada del resto del mundo, por lo que es importante garantizar la coherencia y la complementariedad entre los aspectos internos y externos de la seguridad de la UE". Ver "Comunicación de la Comisión al Parlamento Europeo y al Consejo. La Estrategia de Seguridad Interior de la UE en acción: cinco medidas para una Europa más segura", COM (2010) 673 final, Bruselas, 22 Noviembre 2010, en http://eur-lex.europa.eu/legal-content/ES/TXT/PDF/?uri=CELEX:52010DC0673\&from=ES, p. 3.

${ }^{123}$ Especialmente la Comunicación del Parlamento al Consejo "La Estrategia de Seguridad Interior de la UE en acción: cinco medidas para una Europa más segura”, COM (2010) 673 final.

124 "La lucha contra el terrorismo sigue siendo una prioridad para la Unión Europea, en un año en el que los atentados de Toulouse y Burgas pusieron trágicamente de manifiesto la realidad de la amenaza terrorista". Ver el 
Precisamente, con respecto a la Estrategia de Seguridad Interior de 2015, hay que señalar que el problema del terrorismo es una cuestión sobre la que se sigue trabajando constantemente y sufre revisiones continuas, como se puede ver en el siguiente cuadro:

\section{PRINCIPALES INICIATIVAS LEGISLATIVAS Y POLÍTICAS EN MATERIA DE SEGURDIDAD Y LUCHA CONTRA EL TERRORISMO ${ }^{125}$}

\begin{tabular}{|c|c|}
\hline & Iniciativas \\
\hline \multirow{4}{*}{$\begin{array}{l}2^{\circ} \text { trimestre } \\
\text { de } 2016\end{array}$} & $\begin{array}{l}\text { Revisión de la base jurídica de Eurodac para mejorar sus funcionalidades en lo } \\
\text { que respecta a la migración irregular y el retorno. }\end{array}$ \\
\hline & $\begin{array}{l}\text { Acto delegado sobre la lista negra de la UE para identificar a los terceros } \\
\text { países de alto riesgo con deficiencias estratégicas en la lucha contra el } \\
\text { blanqueo de capitales y la financiación del terrorismo. }\end{array}$ \\
\hline & $\begin{array}{l}\text { Propuesta legislativa para modificar la } 4 .{ }^{\text {a }} \text { Directiva contra el blanqueo de } \\
\text { capitales. }\end{array}$ \\
\hline & Comunicación sobre la prevención de la radicalización. \\
\hline \multirow{2}{*}{$\begin{array}{l}\text { 3er trimestre } \\
\text { del } 2016\end{array}$} & $\begin{array}{l}\text { Iniciativa para mejorar el Centro Europeo de Lucha contra el Terrorismo y } \\
\text { reforzar el trabajo de Europol. }\end{array}$ \\
\hline & $\begin{array}{l}\text { Decisión de Ejecución sobre la interoperabilidad de las Unidades de } \\
\text { Información sobre Pasajeros para los intercambios de datos del registro de } \\
\text { nombres de los pasajeros. }\end{array}$ \\
\hline \multirow{6}{*}{$\begin{array}{l}4^{\circ} \text { trimestre } \\
\text { de } 2016\end{array}$} & $\begin{array}{l}\text { Propuesta legislativa por la que se armonicen las infracciones penales y las } \\
\text { sanciones en materia de blanqueo de capitales. }\end{array}$ \\
\hline & Propuesta legislativa contra los movimientos ilícitos de dinero en efectivo. \\
\hline & $\begin{array}{l}\text { Propuesta legislativa sobre el reconocimiento mutuo de las resoluciones de } \\
\text { embargo y decomiso de activos. }\end{array}$ \\
\hline & Revisión del Sistema de Información de Schengen. \\
\hline & $\begin{array}{l}\text { Propuesta legislativa sobre lucha contra el fraude y falsificación de medios de } \\
\text { pago distintos del efectivo. }\end{array}$ \\
\hline & Revisión del Reglamento sobre los precursores de explosivos. \\
\hline $\begin{array}{l}\text { 1er trimestre } \\
\text { del } 2017\end{array}$ & $\begin{array}{l}\text { Propuesta legislativa para reforzar las competencias de las aduanas y la } \\
\text { cooperación aduanera y luchar contra la financiación del terrorismo } \\
\text { relacionada con el comercio de bienes. }\end{array}$ \\
\hline $\begin{array}{l}2^{\circ} \text { trimestre } \\
\text { de } 2017\end{array}$ & Propuesta legislativa contra el comercio ilícito de bienes culturales. \\
\hline
\end{tabular}

\section{Conclusiones.}

Federica Mogherini en la Estrategia Global para la Política Exterior y de Seguridad de la UE señala las amenazas y los riesgos que atenazan a la UE y señala que el principal camino para luchar contra ellas pasa por fortalecer la Unión. Ese tono (más optimista) contrasta con el que mantuvo el Presidente de la Comisión Europea, Jean-Claude Junker, durante su discurso sobre el estado de la Unión en septiembre de 2016:

\footnotetext{
"Segundo informe sobre la aplicación de la Estrategia de Seguridad Interior de la UE”, COM (2013) 179 final, 10 abril 2013, p. 7.

${ }^{125}$ Ver "Comunicación de la Comisión al Parlamento Europeo, al Consejo Europeo y al Consejo. Aplicación de la Agenda Europea de Seguridad para luchar contra el terrorismo y allanar el camino hacia una Unión de la Seguridad genuina y efectiva", COM (2016) 230 final, ANNEX 1, Bruselas, 20 abril 2016, en http://eurlex.europa.eu/resource.html?uri=cellar:9aeae420-0797-11e6-b71301aa75ed71a1.0014.02/DOC_2\&format=PDF, p. 2.
} 
"I stood here a year ago and I told you that the State of our Union was not good. I told you that there is not enough Europe in this Union. And that there is not enough Union in this Union. I am not going to stand here today and tell you that everything is now fine. It is not. Let us all be very honest in our diagnosis. Our European Union is, at least in part, in an existential crisis." ${ }^{26}$

En ese mismo discurso también hizo referencia al terrorismo y dice precismanete que lo que hay que defender es nuestro estilo de vida, nuestros valores ("what we are is democratic societies, plural societies, open and tolerant"), para decir a continuación que la seguridad que buscamos tiene un precio y que conservar ese grado de tolerancia no puede hacerse a expensas de nuestra seguridad. Señala así el trabajo que su Comisión ha realizado en la lucha contra el terrorismo: "we criminalised terrorism and foreign fighters across the EU, we cracked down on the use of firearms and on terrorist financing, we worked with internet companies to get terrorist propaganda offline and we fought radicalisation in Europe's schools and prisons. But there is more to be done" 127 .

Por su parte, la Estrategia de 2016 dedica bastante espacio a la amenaza terrorista y a las medidas para luchar contra ella y, en general, expone ideas bastantes acertadas sobre ello. Además, sería fácil aducir la escasa longitud de un documento de estas características si alguien señalara que no se trata tal o cual tema. Nombra, aunque sea someramente, los principales puntos en la lucha contra el terrorismo: señala que esta lucha es difícil, que hay que controlar la financiación de estos grupos -y sus vínculos con el crimen organizado-, que hay que luchar contra la radicalización, que hay que promover los valores de la Unión y que hay que buscar el apoyo de los países del entorno de donde provienen algunos de los terroristas. Sin embargo, se echa de menos la mención a la financiación de mezquitas e imanes radicales en suelo europeo. Repetir el mantra de la integración tampoco ayuda, pues no es solo una cuestión de darles una educación y un trabajo digno a los jóvenes musulmanes, sino que detrás también hay toda una serie de causas psicológicas ${ }^{128}$ (depresión, vacío interior, falta de sentido para vivir,...).

Al final de este intento de revisión de cómo se ha tratado el terrorismo en las últimas Estrategias Europeas de Seguridad, especialmente en la de 2016, se puede ofrecer una serie de conclusiones.

En primer lugar, es evidente que la Unión Europea está inmersa en una grave crisis, que no es sólo -ni principalmente- económica sino que es de identidad. El hecho de que el euroescepticismo vaya creciendo de legislatura en legislatura lo demuestra el hecho de que en la eurocámara hay cada vez más representantes contrarios a la UE. La situación originada por el Brexit y por las distintas "amenazas" similares surgidas en otros Estados Miembros puede desembocar en la convocatoria de referenda que acaben por deshilachar la actual UE. La crisis de los refugiados -a quienes se les ha obstaculizado la entrada en territorio europeo no tanto

\footnotetext{
${ }^{126}$ Ver Junker, Jean-Claude: "State of the Union Address 2016: Towards a better Europe - a Europe that protects, empowers and defends", Estrasburgo, 14 septiembre 2016, en http://europa.eu/rapid/press-release IP-163042 en.htm, p.1.

${ }^{127}$ Ibid. p. 6.

${ }^{128}$ Como afirma el islamólogo Olivier Roy, "To my surprise, I find myself increasingly working with psychologists and psychoanalysts". Ver Wiegel, Michaela: "Radicalisation is not the result of failed integration", Qantara, 29 marzo 2016, en https://en.qantara.de/content/interview-with-french-extremism-researcher-olivierroy-radicalisation-is-not-the-result-of.
} 
por "miedo al extranjero" en sí, como por "miedo al terrorista" 129 - ha vuelto a poner de manifiesto que no hay un criterio homogéneo ni una voz común en materia de Política Exterior y de Seguridad.

En segundo lugar, y al hilo de esta crisis de identidad, se encuentran las "guerras culturales". La Estrategia de 2016 incluye en el texto la defensa de la ideología de género ${ }^{130}$. Hay que recalcar que este tema no es prioritario en los Tratados fundacionales ni en los constitutivos, de creación y de reforma ${ }^{131}$. Y, sin embargo, en la actual Estrategia aparece recogido como uno de los valores fundamentales de la Unión, al mismo nivel que la defensa de la libertad, la democracia y los derechos humanos ${ }^{132}$. Es dudoso que en países no occidentales logre imponerse la agenda de la ideología de género; es difícil "vender" la democracia europea a países no occidentales, pero si en el pack se obliga a aceptar la ideología de género, la tarea resulta del todo imposible.

En tercer lugar, la principal causa raíz del terrorismo, como se ha visto a lo largo de estas páginas, no es la económica sino la ideológica -no confundir con la religiosa-. El choque cultural es tan grande entre Occidente y otros Estados del resto del mundo que no es difícil encontrar personas que dan el salto a la violencia como forma de rebelarse frente a lo que consideran una imposición de ver y entender la vida de forma homogénea.

En cuarto lugar, la Estrategia es tan sólo un documento político, un conjunto de frases que pretenden inspirar las políticas futuras. Como tal, no se le puede exigir que sea muy concreto. No obstante, sí acierta en señalar el peligro del radicalismo: "We will work on counter-radicalisation by broadening our partnerships with civil society, social actors, the private sector and the victims of terrorism, as well as through inter-religious and inter-cultural dialogue". Señala también que hay que cortar las fuentes de financiación del terrorismo: "On counterterrorism, we will deepen dialogue with the UN, while building broad partnerships with states, regional organisations, civil society and the private sector on issues such as countering violent extremism and terrorist financing". También acierta en señalar el peligro que suponen los retornados: "This entails shared alerts on violent extremism, terrorist networks and foreign terrorist fighters, as well as monitoring and removing unlawful content from the media", además de volver a poner sobre la mesa el ya viejo debate -aunque aún no agotado, ni mucho menos- del uso de los medios de comunicación social, de la prudencia de la que deben hacer gala, de hasta dónde es lícito informar, qué imágenes se pueden mostrar ${ }^{133}$.

\footnotetext{
129 "Puntos críticos: algunos terroristas han intentado utilizar los grandes flujos irregulares de personas que están teniendo lugar en las fronteras exteriores de la UE en los últimos meses. El enfoque de puntos críticos contribuye a identificar a los individuos que suponen una amenaza para la seguridad de la UE y a distinguirlos de los que necesitan protección. Los puntos críticos y el proceso de reubicación incluyen controles de seguridad integrados y sistemáticos, con el apoyo de FRONTEX y Europol para el registro y la toma de impresiones dactilares a la llegada". Ver Comunicación de la Comisión al Parlamento Europeo, al Consejo Europeo y al Consejo. Aplicación de la Agenda Europea de Seguridad para luchar contra el terrorismo y allanar el camino hacia una Unión de la Seguridad genuina y efectiva, COM (2016) 230 final, Bruselas, 20 Abril 2016, en http://eurlex.europa.eu/resource.html?uri=cellar:9aeae420-0797-11e6-b71301aa75ed71a1.0014.02/DOC 1\&format=PDF, p. 6.

130 "We must also systematically mainstream human rights and gender issues across policy sectors and institutions". Ver Estrategia Global para la Política Exterior y de Seguridad de la UE (2016), p. 11.

${ }^{131}$ En el nuevo art. 2 F, del tratado de Lisboa se introduce un 5 ter: “Artículo 5 ter: En la definición y ejecución de sus políticas y acciones, la Unión tratará de luchar contra toda discriminación por razón de sexo, raza u origen étnico, religión o convicciones, discapacidad, edad u orientación sexual”.

132 "Finally, we will systematically mainstream human rights and gender issues across policy sectors and institutions, as well as foster closer coordination regarding digital matters". Ver p. 51.

${ }^{133}$ Ver "Los horrores de Bataclan: los islamistas cometieron mutilaciones sexuales y torturas", El Español, 16 julio 2016, en http://www.elespanol.com/mundo/europa/20160716/140486642_0.html.
} 
Pero es poco realista, al partir de una base claramente debatible. Así se afirma: "The EU will live up to its values internally and externally: this is the strongest antidote we have against violent extremism"; es decir, se parte de la idea de que nuestro modelo de vida posee una fuerza de atracción intrínseca, cuando lo único que atrae a otros países es nuestra prosperidad económica y no la manera en que se ha llegado a conseguir. Dicho de otra manera, se desean los frutos, pero interesa poco cómo el árbol ha sido capaz de producirlos. Precisamente, es nuestro estilo de vida el que genera rechazo e incluso odio en las personas que al final dan el salto a la violencia y se convierten en terroristas. Son personas que han llegado a tal punto de hastío de nuestra civilización que no les importa perder la vida con tal de manifestar ese odio. Además, hay que recordar que la inmensa mayoría de los ataques perpetrados por yihadistas no han sido cometidos contra occidentales sino contra población musulmana ${ }^{134}$.

Por lo tanto, el documento señala buena parte de las soluciones para acabar con el terrorismo, pero opta por no entrar en un diálogo intercultural auténtico, cosa que por otro lado es imposible desde ciertas posturas maximalistas y planteamientos de "guerras culturales". Sí es cierto que cita ese diálogo a la hora de hablar de contra-radicalización, pero lo hace desde una postura "cómoda", pues antes ya ha fijado una serie de líneas rojas democracia, libertad, derechos humanos, género, etc- difíciles de negociar. Pensar que el terrorismo tiene sólo causas sociales es poco más que equivocado: "Solving conflicts and promoting development and human rights in the south is essential to addressing the threat of terrorism".

Una revisión de las biografías de los que han llevado a cabo actos terroristas y de aquellos otros que han abandonado la senda de la radicalización puede ser muy aleccionadora y sirven para plantear hipótesis sobre si se han radicalizado en Europa, sobre si era su primer contacto -prácticamente- con el Islam, sobre cuáles han sido las motivaciones que les han llevado a dar el salto a la violencia -o a apoyar al terrorismo a través de la captación y/o la financiación-.

También es útil ver cuál es la reacción de los políticos y de la sociedad civil, ver a quién se señala como culpable del acto terrorista, qué tratamiento se le da a las víctimas,... y es especialmente interesante ver la reacción de las autoridades religiosas. Baste como muestra el contraste entre, por un lado, el imán de Nimes, Hocine Drouiche, Vicepresidente de la Conferencia de los imanes de Francia, quien publicó: "Anuncio mi renuncia y mi rechazo a estas instituciones incompetentes que no hacen nada para la paz social y que no dejan de repetir que el extremismo no existe, que es producido por los medios de comunicación" "135; y por otro lado Abdelkader Sadouni, un imán de Niza, quien aseguró que "la discriminación de los musulmanes en Francia, los ataques islamófobos y la prohibición del uso público de los símbolos religiosos son la razón que impulsa a estos jóvenes que no se sienten parte de la comunidad nacional y decidan combatir" ${ }^{\prime 36}$.

Pero también hay que señalar los fallos de este Estado de Derecho -si es que tal concepto se puede aplicar a la UE- pues aunque exista cooperación policial, de inteligencia y judicial,

\footnotetext{
${ }^{134}$ Ver Delman, Edward: “The World's Deadliest Terrorist Organization”, The Atlantic, 18 noviembre 2015, en http://www.theatlantic.com/international/archive/2015/11/isis-boko-haram-terrorism/416673/.

Ver también "Más de un tercio de los muertos en el atentado de Niza eran musulmanes", Público, 19 julio 2016 , en http://www.publico.es/internacional/mas-tercio-muertos-atentado-niza.html.

135 Ver "Dimite el Vicepresidente de los imanes franceses: «Hoy es difícil distinguir entre Islam e islamismo»", Infocatólica, 16 julio 2016, en http://infocatolica.com/?t=opinion\&cod=27027.

${ }^{136}$ Ver "Un imán de Niza: 'Los ataques terroristas son culpa de los franceses"', La Gaceta, 25 julio 2016, en http://gaceta.es/noticias/iman-niza-los-ataques-terroristas-son-culpa-los-franceses-25072016-1250.
} 
recae en cada Estado Miembro la aplicación de sanciones u otro tipo de medidas. ¿De qué sirve saber que "la región de Normandía, junto a Niza, son los dos lugares de donde más franceses han partido para engrosar las filas del Estado Islámico" o que "El Gobierno ha especificado que hay 10.500 personas fichadas en Francia" ${ }^{137}$ si después de recabar tal información sólo se "ficha" a estos sujetos, ¿qué se espera que vayan a hacer después? ¿Qué Estado de Derecho es uno que no puede dotarse de medidas legales para poder tomar medidas excepcionales ${ }^{138}$ ante la situación excepcional generada por este tipo de amenaza? ${ }^{139}$

Al hilo de esto último, es de esperar que la salida del Reino Unido de la UE no afecte en gran medida a la cooperación policial, de inteligencia y judicial que se mantenía con ella dentro de la UE. Esto sería lo más inteligente para ambos lados del Canal de La Mancha. E1 Brexit no debería significar un darse la espalda en esta materia, especialmente en temas de lucha contra el terrorismo, pues así como los delincuentes no conocen fronteras la seguridad tampoco, la seguridad de uno es la seguridad de todos. No sería adecuado que Gran Bretaña fuera santuario de terroristas que huyen de la presión policial del territorio de la UE, como lo fue Francia en los años '80 para ETA; ese escenario no es recomendable para ninguna de las dos partes.

Volviendo a la Estrategia de 2016, dada la brevedad y también ambigüedad intrínseca del documento, no entra en detalles de cómo podría ser esa lucha antiterrorista y si se recurriría a la fuerza militar para luchar fuera de nuestras fronteras contra el origen -y refugio- de los terroristas. Parece que no es esa la intención del documento, y aunque sí habla de la cooperación con la OTAN, de aportar más en materia de presupuesto económico, el sentido del documento indica que no parece que la lucha contra el terrorismo vaya a desarrollarse sobre el terreno por medios militares.

Como se ha visto recientemente, atentar es demasiado fácil, no requiere grandes inversiones, y resulta imposible proteger todos y cada uno de los posibles objetivos de los terroristas. Además, la prevención en ese sentido también es muy difícil pues estaríamos hablando de un control de la ciudadanía en general demasiado profundo y estricto, o bien estaríamos ante un control selectivo de ciertas personas que cumplieran un perfil determinado -perfil que sería construido sobre la base de unos criterios que podrían ser tachados de discriminatorios-.

Por otro lado, la cobertura mediática que tiene un ataque a una sola persona -como los acaecidos en Woolwich (Londres) en mayo de $2013^{140}$ - hace que el efecto deseado -sembrar el terror- se multiplique considerablemente.

\footnotetext{
${ }^{137}$ Ver Martín, Isaac J.: "El segundo asesino de la iglesia de Normandía, fichado como yihadista desde el 29 de junio", El Mundo, 28 julio 2016, en http://www.elmundo.es/internacional/2016/07/28/5798ceb6e2704ec8228b4627.html.

${ }^{138}$ Ver Bleiker, Carla: "Germany closer to confiscating IDs from Islamists", Deutsche Welle, 14 enero 2015, en http://www.dw.com/en/germany-closer-to-confiscating-ids-from-islamists/a-18189490. Ver también "German Former Top Judge against Confiscation of Radical Islamists' ID Cards", Sputnik News, 16 enero 2015, en http://sputniknews.com/europe/20150116/1016983531.html.

139 "Salah Abdeslam, uno de los autores materiales de los atentados de París el 13 de noviembre, y seguramente el terrorista más buscado de Europa, fue localizado en Bruselas, en su barrio de Molenbeek, la madrugada del domingo 15 al lunes 16 de noviembre, apenas dos días después de los ataques. Pero no fue arrestado porque la ley no permite operaciones nocturnas". Ver Suanzes, Pablo R.:"La Policía belga localizó a Salah Abdeslam 48 horas después de los ataques de París pero no lo detuvo porque era de noche", El Mundo, 16 diciembre 2015, en http://www.elmundo.es/internacional/2015/12/16/56714b83ca47414b438b458f.html.

${ }^{140}$ Ver Alonso, Antonio: “El asesinato de Woolwich y Hizb ut Tahrir al Islami: ¿cuál es la conexión?”, GEES, 26 de junio de 2013 , en
} 
En definitiva, se trata de un documento que mejora el análisis con respecto a las anteriores Estrategias en el sentido en que es más realista y recoge buena parte de lo que se ha debatido acerca de este tema en todos los organismos de la Unión. Sin embargo, tiene los déficits propios de un documento que debe ser políticamente correcto y que no toma decisiones arriesgadas, dejando en alusiones vagas la raíz del problema: la lucha ideológica y culturalreligiosa promovida también por predicadores radicales financiados de forma continuada por terceros países.

\title{
Bibliografía Seleccionada
}

Actuación consecutiva a la declaración de los miembros del Consejo Europeo de 12 de febrero de 2015 sobre antiterrorismo: Informe sobre la aplicación de las medidas, 9422/1/15, REV 1, Bruselas, 10 junio 2015, en http://data.consilium.europa.eu/doc/document/ST-9422-2015-REV-1/es/pdf

Actuación consecutiva a la declaración de los miembros del Consejo Europeo de 12 de febrero de 2015 en materia antiterrorista: situación de la aplicación de las medidas, 12318/15, Bruselas, 5 octubre 2015, en http://data.consilium.europa.eu/doc/document/ST-12318-2015-INIT/es/pdf

\footnotetext{
“Agenda Europea de Seguridad: preguntas y respuestas”, MEMO/15/4867, Estrasburgo, 28 abril 2015, en http://europa.eu/rapid/press-release MEMO-15-4867 es.htm,
}

\begin{abstract}
Albaladejo, Javier: "Hacia un nuevo modelo de intercambio de información frente a las amenazas para la seguridad interior de la UE y sus Estados Miembros", Comentario Elcano, 35/2016, 13 julio 2016, en http://www.realinstitutoelcano.org/wps/portal/web/rielcano es/contenido?WCM GLOBAL_CONTEXT=/elcan o/elcano es/zonas es/comentario-albaladejo-hacia-nuevo-modelo-intercambio-informacion-

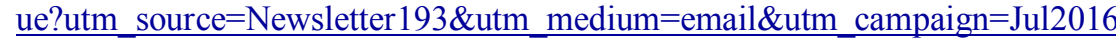

Alonso, Antonio: “El asesinato de Woolwich y Hizb ut Tahrir al Islami: ¿cuál es la conexión?”, GEES, 26 de junio de 2013, en

http://www.gees.org/articulos/el_asesinato_de_woolwich_y_hizb_ut tahrir_al_islami_cual_es_la_conexion_976 $\underline{6}$.

Alonso Marcos, Antonio: "La lucha contra el terrorismo en España: Una estrategia a largo plazo", en Marquina Barrio, Antonio (ed) (2015): La Estrategia de Seguridad Nacional 2013: Un pavimento deslizante. Madrid, UNISCI, pp. 355-402.

Ayrault, Jean-Marc y Steinmeier, Frank-Walter: "A strong Europe in a world of uncertainties", en http://www.diplomatie.gouv.fr/en/french-foreign-policy/european-union/events/article/a-strong-europe-in-aworld-of-uncertainties-28-06-16

Bąkowski, Piotr y Puccio, Laura: 'Foreign fighters': Member States' responses and EU action in an international context", European Parliamentary Research Service, febrero 2015, PE 548.980, en http://www.europarl.europa.eu/EPRS/EPRS-Briefing-548980-Foreign-fighters-FINAL.pdf

Comunicación de la Comisión Al Consejo y al Parlamento Europeo Programa de La Haya: Diez prioridades para los próximos cinco años. Una asociación para la renovación europea en el ámbito de la libertad, la seguridad y la justicia, COM (2005) 184 final, Bruselas, 10 mayo 2005, en http://eur-lex.europa.eu/legalcontent/ES/TXT/PDF/?uri=CELEX:52005DC0184\&from=es,

Comunicación de la Comisión al Parlamento Europeo y al Consejo sobre la captación de terroristas: afrontar los factores que contribuyen a la radicalización violenta, COM (2005) 313 final, Bruselas, 21 de septiembre de 2005, en http://eur-lex.europa.eu/legal-content/ES/TXT/PDF/?uri=CELEX:52005DC0313\&from=ES.

http://www.gees.org/articulos/el_asesinato_de_woolwich_y_hizb_ut tahrir_al_islami_cual_es_la_conexion_976 6. 
Comunicación de la Comisión: "Hacia una estrategia sobre la dimensión exterior del espacio de libertad, seguridad y justicia”, COM (2005) 491 final, Bruselas, 12 octubre 2005, en http://eur-lex.europa.eu/legalcontent/ES/TXT/?uri=URISERV\%3Al16014.

Comunicación de la Comisión al Parlamento Europeo, al Consejo, al Comité Económico y Social Europeo y al Comité de las Regiones - Garantizar el espacio de libertad, seguridad y justicia para los ciudadanos europeos Plan de acción por el que se aplica el programa de Estocolmo, COM/2010/0171 final, Bruselas, 20 abril 2010, en http://eur-lex.europa.eu/legal-content/ES/TXT/PDF/?uri=CELEX:52010DC0171\&from=ES.

Comunicación de la Comisión al Consejo y al Parlamento Europeo: Panorama general de la gestión de la información en el espacio de libertad, seguridad y justicia, COM/2010/0385 final, Bruselas, 20 julio 2010, en http://eur-lex.europa.eu/legal-content/ES/TXT/PDF/?uri=CELEX:52010DC0385\&from=ES.

Comunicación de la Comisión al Parlamento Europeo y al Consejo. La Estrategia de Seguridad Interior de la UE en acción: cinco medidas para una Europa más segura, COM (2010) 673 final, Bruselas, 22 noviembre 2010, en http://eur-lex.europa.eu/legal-content/ES/TXT/PDF/?uri=CELEX:52010DC0673\&from=ES

Comunicación de la Comisión al Parlamento Europeo y al Consejo. Informe final sobre la aplicación de la Estrategia de Seguridad Interior de la UE 2010-2014, COM (2014) 365 final, Bruselas, 20 junio 2014, en http://www.europarl.europa.eu/meetdocs/2014 2019/documents/com/com com(2014)0365/com com(2014)03 65 es.pdf,

Comunicación de la Comisión, de 18 de julio de 2005, relativa a las medidas para garantizar una mayor seguridad en el control de los explosivos, detonadores, material para la fabricación de bombas y armas de fuego [COM (2005) 329 final, en http://eur-lex.europa.eu/legal-

content/ES/TXT/HTML/?uri=CELEX:52005DC0329\&from=ES.

Comunicación de la Comisión de 12 de diciembre de 2006 sobre un Programa Europeo para la Protección de Infraestructuras Críticas, COM (2006) 786 final, 12 diciembre 2006, en http://eur-lex.europa.eu/legalcontent/ES/TXT/PDF/?uri=CELEX:52006DC0786\&from=ES

Comunicación de la Comisión al Parlamento Europeo y al Consejo, de 24 de junio de 2009, sobre el refuerzo de la seguridad química, biológica, radiológica y nuclear en la Unión Europea, en http://eur-lex.europa.eu/legalcontent/ES/TXT/?uri=uriserv\%3Aj10030.

Comunicación de la Comisión al Parlamento Europeo y al Consejo. La Estrategia de Seguridad Interior de la UE en acción: cinco medidas para una Europa más segura, COM (2010) 673 final, Bruselas, 22 Noviembre 2010, en http://eur-lex.europa.eu/legal-content/ES/TXT/PDF/?uri=CELEX:52010DC0673\&from=ES

Comunicación de la Comisión al Parlamento Europeo, al Consejo, al Comité Económico y Social Europeo y al Comité de las Regiones. Agenda Europea de Seguridad, COM (2015) 185 final, Estrasburgo, 28 Abril 2015, en http://eur-lex.europa.eu/legal-content/ES/TXT/PDF/?uri=CELEX:52015DC0185\&from=ES

Comunicación de la Comisión al Parlamento Europeo, al Consejo Europeo y al Consejo. Aplicación de la Agenda Europea de Seguridad para luchar contra el terrorismo y allanar el camino hacia una Unión de la Seguridad genuina y efectiva, COM (2016) 230 final, Bruselas, 20 Abril 2016, en http://eur-

lex.europa.eu/resource.html?uri=cellar:9aeae420-0797-11e6-b713-01aa75ed71a1.0014.02/DOC_1\&format=PDF

Comunicación de la Comisión al Parlamento Europeo, al Consejo, al Comité Económico y Social Europeo y al Comité de las Regiones. Apoyo a la prevención de la radicalización que conduce al extremismo violento, COM (2016) 379 final, Bruselas, 14 junio 2016, en http://eur-lex.europa.eu/legalcontent/ES/TXT/PDF/?uri=CELEX:52016DC0379\&qid=1469830069608\&from=ES, p. 5.

Consejo Europeo de Tampere, 15 y 16 de Octubre de 1999, Conclusiones de la Presidencia, en http://www.europarl.europa.eu/summits/tam_es.htm

Council Framework Decision of 13 June 2002 on Combating Terrorism (2002/275/JHA). 
Decisión del Consejo de 12 de febrero de 2007 por la que se establece para el período 2007-2013 el programa especifico «Prevención, preparación y gestión de las consecuencias del terrorismo y de otros riesgos en materia de seguridad», integrado en el programa general «Seguridad y defensa de las libertades»", 2007/124/CE, Euratom, en http://eur-lex.europa.eu/legal-content/ES/TXT/HTML/?uri=CELEX:32007D0124\&from=ES.

Decisión del Consejo de 17 de marzo de 2015por la que se deroga la Decisión 2007/124/CE, Euratom por la que se establece para el período 2007-2013 el programa específico "Prevención, preparación y gestión de las consecuencias del terrorismo y de otros riesgos en materia de seguridad, integrado en el programa general «Seguridad y defensa de las libertades»”, 2015/457, en http://eur-lex.europa.eu/legalcontent/ES/TXT/?uri=CELEX\%3A32015D0457

Decisión 2008/615/JAI del Consejo de 23 de junio de 2008 sobre la profundización de la cooperación transfronteriza, en particular en materia de lucha contra el terrorismo y la delincuencia transfronteriza, en http://eur-lex.europa.eu/legal-content/ES/TXT/HTML/?uri=CELEX:32008D0615\&from=ES

Decisión Marco 2002/475/JAI .

Decisión Marco 2008/919/JAI del Consejo de 28 de noviembre de 2008 por la que se modifica la Decisión Marco 2002/475/JAI sobre la lucha contra el terrorismo.

Decisión Marco 2008/919/JAI del Consejo, 28 de noviembre de 2008, en http://eur-lex.europa.eu/legalcontent/ES/TXT/HTML/?uri=CELEX:32008F0919\&from=ES.

Delman, Edward: “The World's Deadliest Terrorist Organization”, The Atlantic, 18 noviembre 2015 , en http://www.theatlantic.com/international/archive/2015/11/isis-boko-haram-terrorism/416673/

Díaz Gustavo y Rodríguez, Patricia: “La Unión Europea y el terrorismo islamista”, Revista UNISCI, nº 39 (octubre 2015)

Dictamen del Comité Económico y Social Europeo sobre la «Comunicación de la Comisión al Consejo y al Parlamento Europeo - La política antiterrorista de la UE: logros principales y retos futuros, COM (2010) 386 final.

"El Consejo acuerda su posición de negociación para reforzar el control de las armas de fuego", Comunicado de prensa 322/16 Asuntos de Interior, 10 Junio 2016, en http://www.consilium.europa.eu/es/press/pressreleases/2016/06/10-weapons-strengthen-control/

"El Consejo adopta la Directiva relativa al registro de nombres de los pasajeros (PNR)", Comunicado de prensa 176/16 Asuntos de Interior, 21 abril 2016, en http://www.consilium.europa.eu/es/press/pressreleases/2016/04/21-council-adopts-eu-pnr-directive/

"El Sistema de Información de Schengen (SIS II) empieza a funcionar", Bruselas, 9 Abril 2013, en http://europa.eu/rapid/press-release IP-13-309 es.htm

Estrategia de seguridad Interior de la Unión Europea: Hacia un modelo europeo de seguridad, Marzo de 2010

"EU provides $€ 10$ million to counter radicalisation in the Sahel-Maghreb and stem the flow of foreign fighters from North Africa, the Middle East and Western Balkans", European Commission - Press release, 28 abril 2015 , en http://europa.eu/rapid/press-release IP-15-4866 en.htm

Eurobarómetro $\mathrm{n}^{\mathrm{o}} 83$, Primavera 2015.

European Agenda on Security - State of Play, European Commission - Fact Sheet, MEMO/15/6115, Bruselas, 17 noviembre 2015, en http://europa.eu/rapid/press-release_MEMO-15-6115 en.htm.

FATF: Consolidated FATF Strategy on Combatting Terrorist Financing, en http://www.fatfgafi.org/media/fatf/documents/reports/FATF-Terrorist-Financing-Strategy.pdf

FATF: Emerging Terrorist Financing Risks, Octubre 2015, en http://www.fatfgafi.org/media/fatf/documents/reports/Emerging-Terrorist-Financing-Risks.pdf 
GESI: “Operaciones policiales contra el terrorismo yihadista en España”, en http://www.seguridadinternacional.es/?q=es/content/operaciones-policiales-contra-el-terrorismo-yihadista-enespa $\% \mathrm{C} 3 \% \mathrm{~B} 1$

Gleason, Paul y Gottselig, Glenn (2004): Unidades de Inteligencia Financiera: Panorama General. Washington, Fondo Monetario Internacional.

Global Terrorism Index (2015), en http://www.worldatlas.com/articles/the-global-terrorism-index-countriesmost-affected-by-terrorist-attacks.html.

Hernández, Salvador: "European Authorities Overwhelmed As Hundreds Of ISIS Fighters Return Home”, BuzzFeed News, 25 marzo 2016, en https://www.buzzfeed.com/salvadorhernandez/europe-overwhelmed-byreturning-isis-fighters?utm term $=$.foMbKGzXB2\#.afnmw10509

Informe del Departamento Político de la Dirección General para las Políticas Exteriores de la Unión (2013): The Involvement Of Salafism/Wahhabism In The Support And Supply Of Arms To Rebel Groups Around The World, en http://www.europarl.europa.eu/RegData/etudes/etudes/join/2013/457137/EXPO-

AFET ET(2013)457137 EN.pdf

Informe sobre la aplicación de la Estrategia Europea de Seguridad - Ofrecer seguridad en un mundo en evolución, Bruselas, 11 de diciembre de 2008, en http://www.consilium.europa.eu/uedocs/cms data/docs/pressdata/ES/reports/104637.pdf

Informe sobre la aplicación de la declaración de los miembros del Consejo Europeo de 12 de febrero de 2015, de las Conclusiones del Consejo JAI de 20 de noviembre de 2015 y de las Conclusiones del Consejo Europeo de 18 de diciembre de 2015, 6785/16, Bruselas, 4 marzo 2016, en http://data.consilium.europa.eu/doc/document/ST-6785-2016-INIT/es/pdf

Junker, Jean-Claude: "State of the Union Address 2016: Towards a better Europe - a Europe that protects, empowers and defends", Estrasburgo, 14 septiembre 2016, en http://europa.eu/rapid/press-release IP-16-

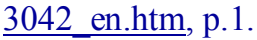

Líneas generales de la estrategia antiterrorista para Siria e Irak, con particular atención a los combatientes extranjeros, 5369/15, Bruselas, 16 de enero de 2015, en http://data.consilium.europa.eu/doc/document/ST-53692015-INIT/es/pdf,

McCants, William (2015): The ISIS Apocalypse: The History, Strategy, and Doomsday Vision of the Islamic State. Nueva York, St. Martin's Press.

"Outcome Of The Council Meeting”, 3367th Council meeting of Foreign Affairs, Bruselas, 9 Febrero 2015, $6044 / 15$

Pietrasanta Sébastien: Rapport Fait au nom de la commission D'enquête relative aux moyens mis en oeuvre par l'État pour lutter contre le terrorisme depuis le 7 janvier 2015 en

http://www.ladocumentationfrancaise.fr/rapports-publics/164000560/index.shtml

Pîrvulescu, Cristian: La política antiterrorista de la UE, SOC/388, Bruselas, 5 de mayo de 2011,

Programa de Estocolmo: Una Europa abierta y segura que sirva y proteja al ciudadano, 2010/C 115/01, 4 mayo 2010, en http://eur-lex.europa.eu/legal-content/ES/TXT/PDF/?uri=CELEX:52010XG0504(01)\&from=ES

"Radicalisation Awareness Network (RAN)", en http://ec.europa.eu/dgs/home-affairs/what-wedo/networks/radicalisation_awareness_network/index_en.htm

Reinares, Fernando y García-Calvo, Carola (2016): Estado Islámico en España, Real Instituto Elcano.

Reglamento (CE) $n^{\circ}$ 2725/2000 del Consejo, de 11 de diciembre del 2000, relativo a la creación del sistema "Eurodac» para la comparación de las impresiones dactilares para la aplicación efectiva del Convenio de Dublin, en http://eur-lex.europa.eu/legal-content/ES/TXT/HTML/?uri=CELEX:32000R2725\&from=ES 
Schott, Paul Allan (2006): Guía de referencia para el antilavado de activos y la lucha contra el financiamiento del terrorismo, $2^{\mathrm{a}}$ ed. Bogotá, Banco Mundial.

Shared Vision, Common Action: A Stronger Europe. A Global Strategy for the European Union's Foreign and Security Policy, en https://eeas.europa.eu/top stories/pdf/eugs review web.pdf

Situación de la aplicación de la declaración de los miembros del Consejo Europeo de 12 de febrero de 2015 en materia antiterrorista, 14734/15, Bruselas, 30 noviembre 2015, en http://data.consilium.europa.eu/doc/document/ST-14734-2015-INIT/es/pdf

Spalek, Basia (ed) (2012): Counter-Terrorism Community-Based Approaches to Preventing Terror Crime. Nueva York, Palgrave Macmillan.

Terrorism and Community Relations, House of Commons, Home Affairs Committee, 14 diciembre 2004, en http://www.publications.parliament.uk

"The ATLAS Network prepares for the biggest anti-terrorism exercise at EU level", European Commission Press release, Bruselas, 17 abril 2013, en http://europa.eu/rapid/press-release IP-13-335 en.htm.

Towards a European Global Strategy. Securing European influence in a changing world, May 13, 2013, en http://www.realinstitutoelcano.org/wps/wcm/connect/4c2675804fc8b86b80b5caccba746acc/EGS_Report.pdf?M $\underline{\mathrm{OD}}=\mathrm{AJPERES} \& \mathrm{CACHEID}=4 \mathrm{c} 2675804 \mathrm{fc} 8 \mathrm{~b} 86 \mathrm{~b} 80 \mathrm{~b} 5 \mathrm{caccba} 746 \mathrm{acc}$

Una Europa segura en un mundo mejor - Estrategia Europea de Seguridad 2003, Bruselas 12 de diciembre de 2003.en

https://www.consilium.europa.eu/uedocs/cmsUpload/031208ESSIIES.pdf,

Weinberg, Leonard y Pedahzur, Ami (2003): Political Parties and Terrorist Groups. Londres, Routledge 